\section{INFLUENCIAS SOCIALES EN LA PERSONALIDAD DE LOS YIHADISTAS DEL 11-M*}

\author{
SOCIAL INFLUENCES IN 11-M JIHADIST \\ PERSONALITIES
}

\begin{abstract}
INFLUÊNCIAS SOCIAIS SOBRE A PERSONALIDADE DOS JIHADISTAS DO 11-M
\end{abstract}

\section{RESUMEN}

La investigación comprende el estudio empírico e interdisciplinar, dentro del perfil de peligrosidad criminal, de la adaptabilidad social de los terroristas yihadistas autores o participantes en el atentado ocurrido en Madrid el 11 de marzo de 2004, a través de los rasgos constatados en fuentes abiertas -Audiencia Nacional, Sentencia 65/2007 e información de los mass media-.

Se ha concluido la investigación a través del tratamiento clínico criminológico que ha permitido tener en cuenta rasgos psicológicos, psiquiátricos, biológicos y sociales, tanto de los terroristas condenados como de aquéllas personas y situaciones que han influido en el constructo de su personalidad criminal.

\footnotetext{
* Artículo de investigación científica, proveniente de investigación extensa, acomodado en contenido y extensión conforme a las normas de publicación, y que presenta resultados respecto a la adaptabilidad social de los autores o partícipes en el atentado ocurrido en la ciudad de Madrid (España), el día 11 de marzo de 2004. Realizado para la Universidad Rey Juan Carlos, con ocasión el periodo de docencia correspondiente al Diploma de Estudios Avanzados, especialización Análisis y Prevención del Terrorismo.

a. Doctor en Criminología, Diplomado en Estudios Avanzados en Análisis y Prevención del Terrorismo, Antropología Médica y Forense, Ciencias Policiales y diversos masters y especializaciones universitarias, es coordinador y profesor, de la Universidad Rey Juan Carlos (Madrid), del Master en Perfiles Forenses de Peligrosidad Criminal. Colaborador habitual en distintos medios de comunicación, viene igualmente colaborando con distintas universidades, la Escuela de Guerra del Ejército de Tierra y agencias internacionales para la lucha contra el terrorismo. Miembro del Grupo de Estudios sobre Seguridad Internacional (GESI), participa en diversos proyectos internacionales relacionados con el terrorismo. Entre sus investigaciones y obras destacan la elaboración de los Perfiles de los Terroristas del 11-M; el Manual de Clínica Criminológica, editado por Tecnos; y la colaboración en el libro La Inteligencia Como Disciplina Científica, editado por la Cátedra de Servicios de Inteligencia de la Universidad Rey Juan Carlos.
}

Jesús Sánchez Gómez a

jessangom@yahoo.es

Fecha de recepción: 9 de abril de 2016

Fecha de revisión: 20 de abril de 2016

Fecha de aceptación: 11 de mayo de 2016
MISIÓN JURÍDICA

Revista de Derecho y Ciencias Sociales Bogotá, D.C. (Colombia)

Colaboradores Externos Internacionales Núm. 11 Año 2016

Julio - Diciembre, pp. 183 - 212

ISSN 1794-600X 
El tratamiento holístico de todo el paradigma de la personalidad investigada lleva a conclusiones respecto a los procesos de socialización, rasgos culturales, países de origen, estancia en otros países en calidad de inmigrantes, religión, agrupación de iguales, relaciones con la delincuencia común y grupos terroristas, así como rasgos fanatizadores o fanatizados, nacionalidad y rangos de edad. La influencia de estas variables, y algunas otras, vienen a concretar la imposibilidad de adaptación social de los terroristas tanto en su cultura de origen como, en mayor medida, en los países occidentales.

Otros rasgos que han sido tratados, de manera transversal, como el egocentrismo, agresividad, labilidad e indiferencia afectiva, apuntan y dejan abierta otra investigación, en proceso, respecto al constructo de personalidad criminal de estos mismos terroristas, cuyas conclusiones serán el resultado de la integración de los rasgos antes referidos con el ahora tratado en la presente investigación; la adaptabilidad social.

\section{PALABRAS CLAVE}

Criminología, personalidad, clínica criminológica, perfil criminal, adaptabilidad social, yihad.

\section{ABSTRACT}

The research covers the empirical and interdisciplinary study, within the framework of criminal risk profile, of the social adaptability of the jihad terrorists involved as perpetrators of or participants in the attack of March 11, 2004 in Madrid through features stated in open sources (National Court Sentence 65/2007, and mass media information.)

The research has been carried out through a criminological clinical approach that has made possible to take into account psychological, psychiatric, biological, and social features of both the condemned terrorists and the persons and situations that have influenced the construct of their criminal personality.

The holistic approach to the whole paradigm of the personality under study leads to conclusions regarding socialization processes, cultural features, countries of origin, stays in other countries as immigrants, religion, association of equals, and relations with common criminals and terrorist groups, as well as fanaticizing or fanaticized features, nationality, and ranges of age. The influence of these variables, and of some others, determines the inability for the mentioned terrorists to socially adapt, in their culture of origin and, to a greater extent, in western countries.

Other features such as egocentrism, aggressiveness, lability, and emotional indifference, which have been dealt with in a collateral way, suggest and leave open another research work, in process, regarding the construct of criminal personality of the same terrorists, whose conclusions will be the result of the integration of the above-mentioned features with the one dealt with in this research: social adaptability.

\section{KEY WORDS}

Criminology, personality, criminological clinic, criminal profile, social adaptability, jihad.

\section{RESUMO}

A pesquisa inclui o estudo empírico e interdisciplinar, dentro do perfil de periculosidade criminal, da adaptabilidade social dos terroristas jihadistas autores ou participantes no atentado em Madrid em 11 de março de 2004, através de traços observados em fontes abertas - a Audiência Nacional, decisão 65/2007 e informações sobre a mídia de massa.

Foi concluída a pesquisa criminológica através de tratamento clínico que permitiu considerar traços psicológicos, psiquiátricos, biológicos e sociais, tanto de terroristas condenados como de aquelas pessoas e situações que influenciaram a construção da sua personalidade criminal.

O tratamento holístico de todo o paradigma da personalidade investigada leva à conclusão sobre a socialização, características culturais, os países de origem, permanência em outros países como imigrantes, religião, grupo de iguais, relações com a criminalidade de massa e grupos terroristas, mesmo como traços fanatizados, nacionalidade e faixas etárias. A influência destas variáveis, e alguns outros vir a perceber a impossibilidade de adaptação social de terroristas, tanto em sua cultura de origem e, em maior medida, nos países ocidentais. 
Outras características que têm sido tratadas, transversalmente, como egocentrismo, agressividade, labilidade e indiferença emocional, estão em execução e deixa aberta outra investigação, no processo, no que diz respeito à construção da personalidade desses mesmos terroristas, cujas conclusões deverão resultar da integração das características acima mencionadas na empresa objeto do presente inquérito; a adaptabilidade social.

\section{PALAVRAS-CHAVE}

Criminologia, personalidade, criminologia clínica, perfis criminais, adaptabilidade social, a jihad.

\section{INTRODUCCIÓN}

La lectura de los estudios realizados por diferentes investigadores, respecto a las posibles causas comunes que construyan la personalidad del terrorista yihadista, vienen concluyendo la inexistencia de rasgos que permitan delimitar un perfil de los mismos. A pesar de ello, pensamos que puede ser de alguna utilidad social profundizar en el estudio del constructo de personalidad criminal del terrorista yihadista.

La investigación pretende aproximarnos al conocimiento del plano sociocultural del terrorista islamista que ha participado en el atentado ocurrido en Madrid el día 11 de marzo de 2004, como parte del paradigma del perfil de peligrosidad criminal del terrorista yihadista.

Consideramos que, hasta el momento, las diferentes investigaciones realizadas adolecen de un tratamiento interdisciplinario, centrándose, casi exclusivamente, en investigaciones de sesgo sociológico y psicológico, fruto de lo cual se obtiene una visión parcial, imposible de determinar la prevalencia de rasgos capaces de construir un perfil criminológico de peligrosidad. No obstante, constituyen un aspecto importante y necesario para la conclusión global del perfil, razón por la que se elige investigar en dicha dirección.

De acuerdo con lo que se ha venido exponiendo, podemos decir que el objeto de la presente investigación supone el estudio, a través de la Criminología, del comportamiento antisocial y delictivo de un individuo. Así, la amplia visión de teorías explicativas de diverso orden, y los factores que inciden sobre ellas, posibilitan observar las diferentes variables que describen el constructo del paradigma de peligrosidad criminal, al objeto de permitirnos enfocar sus conclusiones en inferencias del porqué de la personalidad de los terroristas islamistas, cuyo resultado, tras la investigación particular sobre éstos, ha de ser la concreción del perfil de peligrosidad criminal que ofrezca un conocimiento científico a las autoridades responsables de instar programas de reinserción.

La metodología científica nos ha conducido a observar el fenómeno estudiado y a plantear hipótesis sobre el porqué de determinados comportamientos. La estrategia metodológica utilizada se ha basado en la representación de variaciones o asociaciones que se producen entre distintas variables y la correlación que haya podido existir entre dos o más.

Se parte de un marco disciplinario criminológico que gira en torno al concepto de delito, concebido como el conjunto de interacciones que pueden surgir entre:

- Una persona dispuesta a delinquir

- Un objeto o víctima atractivo

- Y un control social (formal o informal) insuficiente

Siendo el delincuente, junto al entorno social, las áreas de estudio que más han centrado nuestra investigación.

Quiénes son los delincuentes terroristas islamistas que participaron en el atentado de Madrid el día 11 de marzo del año 2004 y las posibles diferencias que existan entre ellos desde un plano social, cuál es su cultura de origen, cuáles los posibles factores que le han llevado o facilitado la comisión del delito, son las áreas estudiadas.

La evaluación criminológica aplicada girará en torno al control de rasgos, tasados ad hoc para la propia investigación, prestando especial atención a la cultura, sexo, edad, educación y familia.

A pesar de la relación de factores biológicos en la génesis de la personalidad, entendemos que la variable prevalente de los entornos sociales sería el elemento etiológico del crimen -capaz de conformar al individuo, de crear las condiciones biológicas y de afinar o acentuar su aptitud delictuosa-, por lo que partimos inclinándonos por considerar las relaciones humanas y culturales como aspectos que ejercen una mayor 
influencia en el proceso tratado, estableciéndose los factores de carácter social o exógeno como factores determinantes.

Entendiendo que la personalidad se concibe como un patrón complejo de características psicológicas profundamente arraigadas, que son en su mayor parte inconscientes y difíciles de cambiar, y que se expresan automáticamente en casi todas las áreas de funcionamiento del individuo, los rasgos estudiados conformarán un patrón idiosincrásico de sentir, percibir, manifestarse y comportarse de un individuo.

Igualmente se entiende que, las disfunciones de conducta que aparecen en los trastornos de personalidad parecen ser el resultado de una deficiencia de la capacidad de la personalidad para enfrentarse a las dificultades de la vida, más que la consecuencia de la aparición o intrusión de alguna noxa o enfermedad psíquica.

Así pues, podemos afirmar que, en general, el comportamiento humano se aprende, siendo cualquier tipo de conducta producto de un extenso proceso de aprendizaje. La delincuencia terrorista, objeto de ésta investigación, se abordará, por tanto, desde esta perspectiva.

Partiendo del concepto de "estado peligroso", entendida como la situación en que se halla una persona que esté a punto de cometer un delito, se puede inferir que la peligrosidad se corresponde con un momento en el que confluyen diversos elementos criminógenos, cuya

acumulación determinará una tensión interna delictiva que delimitará la capacidad criminal de un individuo que parte con una determinada estructura de personalidad.

Consecuentemente, el delincuente que ahora se estudia, terrorista islamista, parece insertar el delito en el desarrollo vital, en su manera de vivir $\mathrm{y}$ en sus relaciones relevantes. De esta manera, no realizaría sus actos como producto de un hecho repentino, ni por casualidad, ni de modo imprevisto. Al contrario, ya mucho antes ocuparía un lugar en el mundo de los pensamientos.

Está inmerso en una circunstancia con entidad histórica; es pasado y es porvenir, es herencia y es futuro. De ahí que para comprenderle tengamos que saber de su desarrollo, de su evolución a lo largo de su historia.

El conjunto de elementos que componen el entorno y conforman, en parte, la personalidad terrorista, va a depender de la personalidad previa del sujeto, condicionada, entre otros, por el medio en que vive, y estructurada, en parte, por la herencia biológica y los lugares en que nació y vivió.

Siendo conscientes que el acercamiento a la realidad es una práctica complicada y difícil, partimos asumiendo que lo que intuimos quizá no sea cierto, por lo que nos acercaremos a la realidad a través de un conocimiento científico, mediante una aproximación tanto a la realidad asentida como a la realidad experimentada, por lo que nos auxiliaremos del apoyo lógico y empírico que nos aportan diferentes ciencias.

Se pretende orientar las áreas teóricas, sobre las que se construye la personalidad peligrosa, desde un plano social, así como identificar, a través de las mismas, las variables y atributos que nos permita concretarlas para su estudio, de manera que los elementos divergentes, de los diferentes conceptos y teorías, sean presentados de forma conjunta y considerada globalmente como un todo integrado.

Entendemos, por tanto, que el objetivo principal es centrar, como paradigma, el área social de la personalidad.

La labor investigadora se llevará a cabo con conocimiento expreso del pensamiento crítico, por lo que se identificará en apartado especial las variables extrañas.

\section{MÉTODO CLÍNICO}

Las características empíricas e interdisciplinarias representan dos aspectos del método de estudio de la Criminología, cuya ciencia tiene entre sus funciones conocer $y$ explicar la realidad, para lo que se auxilia del método científico. De esta manera, tras obtener la información y tratarla estadísticamente, interpreta el objeto de estudio.

Sobre estas bases, la criminología clínica contribuye al conocimiento del delincuente y de los individuos socialmente peligrosos, mediante el 
estudio de la personalidad criminal y antisocial y del medio ambiente social criminógeno.

Resulta evidente que la Criminología no es una ciencia exacta, siendo su principal objeto mostrar conclusiones sobre la realidad.

En la investigación realizada se atiende a los aspectos psico-sociales derivados de la cultura, de origen o adquirida, y la influencia del medio, obteniéndose un enfoque de la adaptabilidad social, componente del constructo de personalidad que modula el comportamiento del sujeto.

El diagnóstico clínico criminológico parte de la base que cada delincuente se trata de una individualidad biológica, psicológica y social, en donde cada uno llega de un modo distinto a la comisión de la conducta delictiva y por tanto debe ser estudiado, conocido y comprendido, desde su historia familiar, personal y social, lo cual, en definitiva, nos podrá brindar un diagnóstico criminológico en cuanto al perfil de personalidad y génesis de la conducta delictiva, por ello, nos vamos a auxiliar de la encuesta social, se intentará despejar la parte de la herencia y del medio, en la génesis de la delincuencia, y reconstruir la historia del sujeto y de su familia, por tanto, de su delito.

En consecuencia, se utilizarán unas variables, previsibles de ser ajustadas a herramientas probadas, provenientes de catálogos aceptados pericialmente para la discriminación de rasgos (especialmente: CIE-10, DSM 5,) que inciden en el constructo de personalidad, que posibilitan su estudio de manera atributiva $y$, en consecuencia, permiten sustento doctrinal.

Obtenido los datos de cada sujeto, a través de las herramientas descritas, se pondrán en consideración al objeto de obtener semejanzas y diferencias con respecto al fin de la investigación.

El derecho al honor, la intimidad y la propia imagen, como garantía constitucional, nos hace identificar a cada sujeto estudiado mediante la asignación de una letra.

\section{HIPÓTESIS}

De los datos apriorísticos de la conducta que pudieran describir los rasgos de personalidad del terrorista islamista estudiado, observamos que:
La rigidez en su creencia pudiera provenir de un yo infantil e inseguro, intolerante, cargando su verdad de afecto, y para compensar su falta de racionalidad razona con la pasión de su creencia, así no se permite dudar, ni puede cuestionarse su credo, cuya duda derrumbaría el esquema de su violencia, que se ha transformado en algo monolítico para defenderse de su propia inseguridad (García Andrade, 1982:312).

Su adhesión a ideologías religiosas radicales, dogmáticas y monoteístas, le lleva a una interpretación radical de Islam, permitiéndole cualquier acto capaz de acercarle a las metas estimadas, amparado, a su vez, por una presunta aprobación de la violencia por cuestiones religiosas que utilizan dichas razones para justificar las acciones terroristas.

Así, el miedo al error y la angustia que pudiera suponer la libre elección de la decisión no planteará problemas de duda.

Parece alejado y con predisposición a obstaculizar la verdad, propio del sentimiento mágico infantil de la omnipotencia, lo que le lleva a un narcisismo conservador y no expansivo -que es donde radica la socialización-.

El terrorista yihadista parece ser un personaje joven, integrado en un grupo que adquiere una especial significación al amparar y enmascarar el anonimato, en el que es más fácil adoptar conductas asociales $-y$ por supuesto matar- ${ }^{1}$.

Entendemos que estos terroristas yihadista no podrían existir sin ese otro personaje con el que forma un extraño binomio, el líder, que llega a intelectualizar el crimen, dando así una supuesta cobertura al terrorista, pero amparándose en la distancia, con una frialdad aparentemente apasionada.

Parecen ser sujetos cuyo fanatismo se nutre del fracaso personal previo $^{2}$, pretendiendo destruir

1. Este rasgo se pretende constatar en las cárceles. Al disminuir la fuerza del grupo y diluir al sujeto terrorista entre el resto de la población reclusa, la que crea en él sentimientos de inseguridad al verse desprotegido y desamparado, forzará a una relación no tan impersonal, como las que mantienen los grupos terroristas con el resto de los compañeros de prisión, reduciendo así esa peculiar hipertrofia del Yo, una de sus especiales barreras y defensas. El grupo tiene además un carácter claro de funcionalidad, y es que disminuyen los obstáculos para la comisión del crimen entre agresores y víctima.

2. Obsérvese lo tratado en este texto, 2.1.2. Fechay lugar de nacimiento. 
a la sociedad que no les estimó lo suficiente, potenciando en ellos un continuo descontento.

Consideramos que en esta personalidad terrorista existe un entorno favorecedor de su despliegue, siendo fundamental para ello que sea maternalista, es decir, que no se corresponda con los elementos esenciales del matriarcado o patriarcado, en los que la autoridad es siempre clara y no se discute; la madre adopta un papel eminentemente castrante (Losada y Bayt, 1993:45), con pocas posibilidades de actuación fuera de un clan fuertemente cohesionado, y el padre sólo pierde el poder con la muerte, pero, sin embargo, donde la madre es condescendiente y permisiva, arropando las debilidades del hijo, lo que le hace más cruel e híper hostil. Así, las sociedades maternales persiguen fundamentalmente los delitos económicos y contra la propiedad (García Andrade, 1982:315-316) ${ }^{3}$, pero son débiles $y$ consentidoras con el terrorismo.

Convenimos con Sykes y Matza (1957:664670) sobre las técnicas de neutralización o exculpación que utilizan este tipo de terroristas para dar consistencia a su conducta, de esta manera, expresarán la negación de la responsabilidad, negación del delito y la víctima (descalificación), rechazarán a aquellos que condenan la acción, apelarán a lealtades debidas en defensa de la necesidad de la conducta, dirán defender un valor en pro de la justicia y la necesidad de la ley (su Ley), mediante el argumento de tener derecho y obligación a hacerlo.

\section{Variables extrañas}

Referidas a rasgos de personalidad del terrorista estudiado

- Influencias sociales no conocidas.

- Influencias doctrinales no conocidas.

- Influencias familiares no documentadas.

- Tipo de disciplina familiar no documentada

3. En la sociedad árabe, eminentemente maternal -que no matriarcal, ni feminista-, parafraseando al profesor García Andrade: "[...] "la mamá" a diferencia de la madre, no es tolerante sino transigente, el miedo a perder al hijo la hace sobre-protectora, blanda, temeraria [...].

[...] Este sistema maternal es permisivo con todo, salvo la directriz económica [...]. El terrorista [...], encuentra un buen caldo de cultivo en este sistema, carece del padre y de la madre necesarios (nota del autor: especialmente en los lugares de emigración), como figuras tutelares para el desarrollo armónico de su personalidad [...]. Por ello no tiene nada de extraño que las sociedades maternales, [...] persigan y penalicen más los delitos económicos y contra la propiedad, que aquellos que atentan contra la integridad y la vida [...]"(García Andrade, 1982:315-316).
Referidas a la presencia del investigador

- Posición religiosa desconocida para el sujeto estudiado.

- Cultura occidental vs. Cultura islámica.

\section{Control de las variables extrañas}

Referidas a respuestas del terrorista islamista estudiado

- Para el control de las variables sujeto orgánicas se parte de la confección única de entrevista estructurada y cerrada.

Referidas a la actuación y respuesta de los sujetos investigados

- Se contrastan los resultados de las variables dependientes con la moda estadística a través de bases de datos.

Referidas al investigador

- Se plantean variables definidas y revisadas. Referidas a la obtención de datos

\section{DELIMITACIÓN}

Sujetos autores, o colaboradores con el terrorismo yihadista, condenados por el atentado ocurrido el 11 de marzo de 2004 en Madrid.

\section{DESARROLLO DE LA DISCUSIÓN ADAPTABILIDAD SOCIAL}

\section{RECOGIDA DE DATOS}

Quizá la recogida de datos haya supuesto en la investigación una tarea de las más arduas, tanto por su complejidad como por los obstáculos que se han tenido que ir solventando y la perseverancia que se ha necesitado.

A su vez, la información de documentos oficiales, así como autos y sentencias, facilitados por la Audiencia Nacional (Procedimiento Sumario, 20/04; Expediente Sumario, 202004 ) y la Fiscalía (DGP, 2004) con datos particulares de enorme interés, en la medida que describían conductas e informaban de rasgos concretos de valor criminógeno, y la posibilidad de contrastarlos con familiares $y$ abogados defensores de los imputados ${ }^{4}$, nos llevó a determinar esta información como principal, así como a centrarnos en ella, descartando otras

4. Especial agradecimiento a D. Antonio Alberca, abogado defensor de Rafa Suhiery otros 
que provenían de fuentes periodísticas cuya aproximación a la realidad no siempre coincidía.

Con todo ello se pudo contestar a gran parte de los ítems que se necesitaba de cada uno de los terroristas que se pretendía investigar.

\section{TRATAMIENTO DE DATOS}

El diseño de la investigación ha perfilado, desde el principio, la posibilidad de ofrecer la discriminación de aquel ítem que ofrezca información pertinente. Así, para la investigación del aspecto que ahora se estudia, los datos reflejados nos permiten observar frecuencias, modas, dispersiones, porcentajes, afinidad y tendencias capaces de enfocar las muestras y el censo a determinadas conclusiones.

Como refleja el gráfico número 1 (en anexo, p. 204), la distribución del sexo, en los trece terroristas condenados por el atentado ocurrido el 11 de marzo de 2004 en Madrid, supone una frecuencia total de varones frente a las mujeres, determinando esta característica el 100\% del censo.

El tratamiento singular que se ha venido dando a cada uno de los rasgos tratados nos ha posibilitado, tras haberse observado en los sujetos el enfoque desviado y la nocividad de dichos rasgos, efectuar una adición de los mismos, de forma que se corresponda, en la representación, el mayor número con la acumulación de las variables criminógenas. De este modo, en la documentación obrante en el Juzgado Central de Instrucción no 6, Audiencia Nacional, Madrid, Expediente, Sumario 20/04, Carpeta 11 Documentación desclasificada, así como en la misma Audiencia, Sala de los Penal, Sentencia 20/04, se observa cómo los sujetos C, M y $\mathrm{N}$ presentan una menor capacidad de adaptación. El análisis histórico-sociológico que seguidamente se realiza en el epígrafe Análisis de datos ${ }^{5}$, respecto a determinadas circunstancias de Marruecos, permitirá observar factores de incidencia en el constructo de las personalidades investigadas.

Las variables extrañas ${ }^{6}$, predictoras y de criterio que pudieran derivarse de las de covarianza son, en todo caso, controladas, y no influyen en el presente

5. Vid. Op. cit. Subepígrafe 2.1.1.

6. Tipo, gravedad y reincidencia, o no, en el mismo delito. Lugar de residencia tras la etapa de formación de la personalidad, etcétera. rasgo más allá del delito, toda vez que la conclusión a la que se pretende llegar en el presente apartado, no es tanto la mayor o menor severidad de peligrosidad como el mayor o menor posicionamiento del sujeto a adaptarse socialmente.

\subsection{Análisis}

\subsubsection{Factor Género}

Conscientes de la unicidad de cada ser humano y de la diferencia actitudinal de cada sujeto, que la totalidad del censo estudiado refiera a varones, con independencia que en todos los países haya más hombres delincuentes que mujeres, nos enfoca el estudio de rasgos y circunstancias que van a posibilitar contestar algunas de las hipótesis planteadas en la presente investigación.

Las premisas de un adecuado control paterno y la imitación de los padres, respecto a la adaptación social del sujeto, nos hace prever un proceso de socialización particular del varón, así como una particular interacción entre éste y el resto de las figuras masculinas de la fratría, especialmente del varón que ejerce la tutela.

Concluyendo los estudios epidemiológicos el peso que supone, a favor del varón, los factores socioculturales en la determinación de la disposición agresiva de los diferentes sexos, especialmente en aquellas culturas que establecen una socialización diferente para hombres y mujeres, así como la interacción del sustrato biológico en la misma dirección que se viene apuntando, las influencias sociales ponen de relieve cómo la falta de integración social influye en la conducta delictiva y en los procesos de adaptación social de los individuos.

Tal como argumentaban Hirschi (2002), Sykes y Matza $(1957,2003)$, la adaptación social proviene de la existencia de vínculos afectivos con personas integradas socialmente.

Si para estos autores la ausencia de creencias, de normas y vínculos sociales que prohíban delinquir, dirigía al sujeto a ese destino en un proceso de deriva, en nuestra investigación, el apego que el terrorista yihadista establece emocionalmente con aquellas personas a las que admira y con las que se identifica, desde la posición de un yo inmaduro, le hace participar de 
las mismas creencias que su líder y adquirir los compromisos por éste demandados.

Así, el terrorista yihadista no vendría sustentado por una falta de apego a los padres, especialmente al padre, por las razones que seguidamente se verán, sino todo lo contrario, por la existencia de una gran vinculación, de ahí que el tipo de injusto que cometen tenga un fin concreto; la insurgencia, circunstancia que caracteriza la especificidad del delito terrorista. Esta identidad emocional, con los valores aprehendidos culturalmente a través de la socialización familiar, nos lleva a observar que:

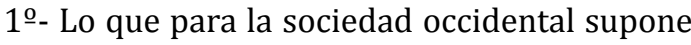
un proceso revolucionario, para el terrorista yihadista su acción se enmarca en un contexto de conformidad con sus valores subculturales, estableciendo como legítimo, para la consecución del fin buscado, el modus realizado.

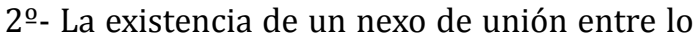
psicológico y lo sociológico.

Tal como describe Parsons (1984), el comportamiento desviado -desde la perspectiva de un occidental- será fruto de la acumulación de tensiones en el sujeto, tendentes a liberarlas mediante los procesos influidos por la dinámica del grupo familiar primario.

$3^{\text {- }}$ Los estados emocionales como la ira, la frustración o el resentimiento construyen una inadecuada relación con el entorno, pudiendo derivar en ejecución de acciones correctivas contra las fuentes que les ocasionan las tensiones emocionales.

4-. Los antecedentes distantes de una conducta agresiva vienen determinados por las experiencias infantiles -familia, grupo de amigos, escuela, entorno- y la propia personalidad del sujeto, modulado por factores biológicos.

5- La teoría del aprendizaje social establece que la conducta violenta refiere como fuente de modelo a la familia, asumiéndose las respuestas predominantes de su entorno tendentes a la imitación de roles.

$6^{0}$ - Estudios realizados por investigadores como Jordán (2004:90), vienen a poner de relieve y concluir, al igual que la presente investigación, el rasgo masculino como elemento identitario de la práctica totalidad del terrorista yihadista.
La forma de entender este rasgo -varón- en la persona del terrorista yihadista obliga a referirnos al mismo desde una perspectiva etnográfica, surgida de la influencia que sobre la cultura de una sociedad, concretamente la islámica, ejerce la religión, en este caso, el Corán.

Más allá de su título, el Corán ofrece un texto desconocido para la mayoría de las personas que no profesan la religión islámica, la cual relata y refiere obligaciones, creencias y costumbres de pueblos dirigidas al aprendizaje doctrinal, reflejando conductas a las que establece verdaderos códigos. Así pues el Corán, a pesar de ser un texto sagrado y religioso, es un texto histórico y costumbrista, cuyo enfoque determina el fin al que se dirige; el control social de manera expansionista, obligando a los que profesan el Islam a extenderlo por toda la geografía mediante el yihad y autorizando el empleo de la violencia contra los no creyentes (Corán, 9:5,29; 8:39) ${ }^{7}$, es así, hasta el punto que, muchos estudiosos, entre los que nos encontramos, consideran el yihad como el sexto pilar del Islam.

Las sociedades se crean y desarrollan a consecuencia de la existencia del Derecho, así la elaboración de las normas en el Islam provienen de las fuentes de la jurisprudencia, las cuales se corresponden con dos tipos: el Corán y el hadiz, por un lado, y el ijma o acuerdo unánime de juristas por analogías derivadas de precedentes. A ello podría añadirse la fuente de la equidad y las costumbres que forman la base de determinadas escuelas -Hanifí y Malikí-. Como venimos observando, para la sociedad islámica el Corán es la mayor de las fuentes de la Ley, a cuyo texto, por ser "palabra de Dios", se le debe obediencia. Así, a la pregunta de Rasulullah, el texto responde "¿Por qué habría de desear otro juez que Allah cuando es Él quien ha hecho descender para vosotros el Libro clarificador?" (Corán, 6:114).

De igual modo, en la aleya 115 , de la misma Sura, inquiere "La palabra de tu Señor es de una

7. Cfr. Respectivamente:

" $Y$ cuando hayan pasado los meses inviolables, matad a los asociadores donde quiera que los halléis. Capturadlos, sitiadlos y tendedles toda clase de emboscadas..."

"Combatid contra aquellos, de los que recibieron el Libro, que no crean en Allah ni en el Último Día, no hagan ilícito lo que Allah y Su Mensajero han hecho ilícito y no sigan la verdadera práctica de adoración..."

"Y combátelos hasta que no haya más oposición y la práctica de Adoración se dedique por completo a Allah" 
variedad y justicia completas, no hay nada que pueda hacer cambiar Sus palabras".

Enmarcada la perspectiva que subyuga todo proceso de socialización en territorio islámico, se observa cómo a la mujer se la desplaza a un rol social secundario, con una marcada preeminencia del hombre sobre ellas, relegándolas a un papel sexual y de crianza. Nos referimos por tanto a una subcultura de corte patriarcal, reflejo de lo prescrito por Alá en diversos momentos del Corán, donde se las obliga a una disminución de su libertad personal (Corán, entre otras, 33:59; 24:31), sobresaliendo la figura masculina hasta el punto de determinar que sea el hombre quien tenga preeminencia sobre la mujer. De este modo puede forzarla a obedecer, mandarle, ordenarle que se quede en su cuarto e incluso pegarle (Corán, 4:34). En este marco la mujer es inferior en los testimonios (Corán, 2:282), en las herencias (Corán, 4:11,12) la mujer vale exactamente la mitad que el hombre.

Vista la influencia cultural del hombre en la sociedad islámica, parece concluyente que sean estos, y no las mujeres, los destinados a extender la Sharía -ley islámica proveniente del Coránmediante la yihad.

Consecuencia de lo referido en el presente apartado cabría observar cómo en situaciones donde el niño vive, respecto a la madre, un hospitalismo atenuado por razones sociales -por obligaciones laborales de la madre, ausencias prolongadas, o un rol como el descrito anteriormente con ocasión de la religión islámicaésta no llega a establecer la relación íntima con el hijo, sin trasmitirle, en este caso, el apoyo maternal, a través del cual recoge la información genética y la socio genética, capaz de hacerle incorporar el ambiente a su ser (García, 1973:25). A sensu contrario, la especial influencia del padre llevará al menor a una socialización altamente competitiva y virilizante (García, 1973:131).

Es el padre, especialmente en culturas como las descritas, quien socializa al hijo, el cual adolece, en el constructo de su personalidad, de aquellos rasgos necesariamente influidos por la madre. Así el padre potenciará aquellos conceptos relacionados con la figura paterna, tales como la coherencia lógica. "El padre es el jefe, el bien, el coordinador, el origen de los valores" (García, 1973:26), asistimos así a la formación de la conciencia moral que regirá la lucha del hombre contra la tendencia inconsciente de los instintos en buscar el placer. De este modo el hijo, en ausencia del factor maternal, irá introyectando la figura paterna (García, 1973:27), pudiendo potenciarse un sesgo socialmente patológico que hace del individuo un ser con dificultades de adaptación social.

\subsubsection{Fecha y lugar de nacimiento}

La conducta humana de un individuo sólo puede ser entendida en términos de la conducta de todo el grupo social del cual él es miembro, puesto que sus actos individuales están involucrados en los actos sociales más amplios, que van más allá de él y que abarcan a otros miembros de ese grupo.

Dentro de la violencia colectiva, cobra una especial importancia la identidad social que posea el individuo, ya que la imitación de estas conductas dependerá del grado en que el sujeto se siente identificado con la pertenencia al grupo, más que por el resultado que se obtenga.

Así, y dado que las personas son capaces de modificar los significados y los símbolos que usan en la acción y la interacción sobre la base de su interpretación de la situación, se ha de realizar el estudio descriptivo de la cultura de una comunidad, o de alguno de sus aspectos fundamentales, bajo la perspectiva de comprensión global de la misma.

Partimos de la base de entender que cualquier especialista que desee comprender los actos de las personas precisa ver los objetos como ellos lo ven, ya que de lo contrario sustituirá los significados de dichos objetos por sus propios significados. Las personas actúan con respecto a las cosas basándose en el significado que éstas encierran para ellas, y no sobre el que poseen para el especialista.

Por estas razones se considera pertinente el estudio de la fecha y lugar de nacimiento desde un planteamiento analítico-etnometodológico, descubriendo y desenmascarando, tras la fachada de los tópicos cotidianos, los factores ocultos, intentando mostrar las reglas del orden social que de manera influyente han participado en la personalidad del sujeto terrorista yihadista.

Como se puede apreciar en los gráficos 2 y 3 (en anexo, p.p. 204 y 205), el rango que presenta la fecha de nacimiento es amplio -20 años-, si bien 
tras el estudio de la acumulación de frecuencias y la dispersión, observamos que se reduce, de forma que en cinco años se acumula el 53,8 \% de los sujetos -gráfico 3 (en anexo p. 205)-.

Dado que las edades con valores $|25|$ y $|29|$ determinan el peso -38,4 \%- de la población estudiada -gráfico 6 (en anexo, p. 206) - y que la moda -29 años- y la marca de clase - 28 años en el intervalo |25-31|- soportan significativamente $-61,5 \%$ - la edad de los sujetos en el año 2004 -año del que se extraen los datos debido a su detención-, nos ayuda a concretar el periodo de vida en que se formó la personalidad del individuo -gráficos 7 y 8 (en anexo, p. 207)-, de tal suerte que al situarse en el año 1975 la fecha de nacimiento derivada de la moda, y considerando la edad de 20 años -final de la adolescencia- como finalizadora del proceso de configuración total de la personalidad, nos encontramos, hasta el año 1995, las influencias que hayan podido recibir del entorno dirigidas a la adaptabilidad social, siendo las influencias posteriores de naturaleza eminentemente reactivas.

Igualmente, se considera necesario estudiar la fuente influenciadora -entorno- al considerarse la causa directa socializadora de los terroristas investigados.

De la misma manera que se ha determinado el periodo de tiempo en que se ha influido sobre la personalidad del terrorista estudiado, se estima que la edad de aquellos con capacidad para influir debieran haber formado su personalidad en las décadas comprendidas entre 1930 y 1950, sin olvidar, no obstante, que durante el tiempo que se ejerce de agente socializador seguía recibiendo influencias capaces de determinar conductas.

La generalidad de las fechas ha de concretarse con el lugar de nacimiento. Así en Marruecos y Siria -gráfico 5(en anexo, p. 206) -, y especialmente las ciudades de Tánger, Tetuán, Damasco y Homs -gráfico 4 (en anexo, p. 206) -, enfocan el ámbito socio-cultural necesitado de estudio por su determinada influencia en los constructos de personalidad investigados.

-Aspectos culturales de Marruecos y procesos de socialización:

Situado en el norte del continente africano y separado de Europa por el estrecho de Gibraltar ha supuesto una región estratégica para todas las culturas.

De clara influencia islámica desde finales el siglo VII, las diferentes dinastías gobernantes derrumban el país a causa de un largo periodo de guerras civiles.

Es en el siglo XVII, bajo la dinastía Alauí, cuando Marruecos empieza a estabilizarse, época en que se anexiona la ciudad de Tánger.

La localización estratégica y sus riquezas supusieron el interés para la colonización, en especial para las potencias europeas, llevando a establecer una pugna desde mediados del siglo XIX a mediados del XX a Francia, Inglaterra, Alemania y España.

A pesar de la autonomía marroquí como estado, los protectorados llevados a cabo en la primera mitad el siglo XX sobre su territorio, por parte de España y Francia, supusieron en la práctica que se convirtiera en colonia de éstos, especialmente desde 1930.

La resistencia a los protectorados y a la ocupación colonial europea supuso enfrentamientos armados con la población marroquí que, bajo el amparo de partidos nacionalistas, basaban sus ideales en la creación de un estado independiente, hecho que se concretó tras extenderse el nacionalismo, con el apoyo de la Liga Árabe, en 1956, a las ciudades de Tánger y Tetuán, entre otras, constituyéndose en una monarquía constitucional y de derecho divino al mismo tiempo.

El Rey, como Comendador de todos los creyentes, se atribuye la máxima autoridad religiosa islámica, cuya doctrina, fundamentalmente sunní, profesa la mayoría de la población.

- Décadas 1930-1950:

Obtenida la ciudad de Tánger el carácter de ciudad internacional en 1923, el aumento del número de colonos franceses y españoles a partir de 1930 se incrementa como consecuencia de convertirse en centro comercial y diplomático.

Gobernado Marruecos por Mohammed V (19271961), las rebeliones beréberes contra intereses españoles supuso la norma a partir de 1931. 
Mientras se daban las rebeliones a las que se viene haciendo referencia, Marruecos se colonizaba. Tánger obtenía el carácter de ciudad internacional -1923-, sufriendo los avatares de la Segunda Guerra Mundial respecto a su gobierno y hasta la independencia de Marruecos.

Tetuán, ciudad cercana a Tánger, agrícola y manufacturera, se constituía capital del protectorado español en Marruecos -1913 a 1956-, circunstancia que influyó decisivamente, al igual que para Tánger, en el extenso conocimiento del idioma español.

Supuso la Segunda Guerra Mundial un influjo decisivo en la ciudad de Tánger, dado el carácter multicultural, de neutralidad política y libertad comercial, atrayendo, de este modo, tanto capitales como actividades de espionaje durante la guerra fría y otros periodos conflictivos.

Internacionalmente, estas décadas se caracterizaron más por sus convulsas situaciones que por aquellas otras que pudieran ayudar al progreso social de Marruecos, así, las dictaduras rusa, alemana, española y china, las crisis inflacionarias, en países como Alemania, y la Segunda Guerra Mundial supuso una introyección religiosa a sus habitantes.

- Décadas 1950-1970:

El carácter formado en la población marroquí durante las décadas anteriores va a contrastar con las posibilidades de construir un nuevo perfil debido a las épocas de bonanza vividas en el periodo ahora estudiado.

Si anteriormente destacaban las dictaduras, la colonización y las crisis, ahora serán significativos los pactos; la creación de la OTAN, el Pacto de Varsovia, la división de Alemania, el Plan Marshall para la recuperación europea, la Declaración Universal de los Derechos Humanos de la ONU, el pacto de amistad entre la Unión Soviética y China, la fundación de la Comunidad Económica Europea, el nacimiento de la OPEP y las manifestaciones en Washington por los derechos civiles.

Los avances sociales que supuso lo anterior, tras la finalización de la Segunda Guerra Mundial, no afectaron por igual a todos los países. En concreto Marruecos, a pesar de obtener su pretendida independencia, no logra evolucionar al ritmo de la mayoría de los países occidentales.
Todo lo contrario, su carácter expansionista le hace guerrear contra España -guerra de Ifni, 1957 a 1958- o contra la recién independizada Argelia -1963-, la cual había obtenido dicho carácter por la libertad que le otorgó el gobierno francés, tras la negación de entrega de dicho territorio a Marruecos, consecuencia, entre otras, a la rebelión árabe contra los franceses durante el verano de 1955, en la que sufrieron una oleada de atentados terroristas, llevados a cabo por el Armée de Libération, creado en El Cairo (Egipto) para combatir la ocupación del Frente Nacional de Liberación en Argelia.

Proclamada la independencia de Marruecos -1961- se produjo la desamortización de las tierras pertenecientes a los colonos europeos, se fomentó la escuela, la formación profesional y la universidad. A pesar de todo, la falta de actitud democrática de Hassan II (1961-1999) llevó a este a redactar, hasta obtener una "a medida", tres constituciones, tantas como el número de intentos de asesinato sufridos. La corrupción y la represión social constituirán en esa época el clima social de la zona.

La característica árabe de la población marroquí supuso el acercamiento ideológico pan arábico que, con matices, se implicaría ideológicamente en las sucesivas guerras árabe- israelíes ${ }^{8}$.

- Periodo 1970-1995:

Este periodo, que comprende la etapa de construcción de personalidad del terrorista yihadista estudiado, va a caracterizarse por el asentamiento de las democracias occidentales, la consolidación de los Derechos Humanos -acuerdos de desarme nuclear, fin del apartheid, reunificación de Alemania, paz entre Israel y la OLP-y los avances tecnológicos, también se va a caracterizar por el incremento de posiciones radicalizadas, tanto de índice nacionalista como religiosa.

En los países de influencia árabe, la ideología expansionista supone un incremento de tendencias y actividades terroristas al hilo de una pretendida obligación teológica de recuperación de territorio.

8. En estas guerras participaron Inglaterra y Francia. Posteriormente entró en la contienda Estados Unidos al objeto de contrarrestar el apoyo dado a Egipto por la Unión Soviética 
De esta manera Marruecos, con elevado porcentaje de población musulmana, no termina de definir su posición con occidente. Tánger, segundo centro industrial de Marruecos, con una economía basada en el turismo participado económicamente por inversiones extranjeras, cuenta con un sistema educativo comparativamente alto, conviviendo el sistema marroquí, español, francés, norteamericano y británico. Seguramente por ello, la ciudad ha sido centro de éxodo rural de la región, con una población cuadruplicada en las últimas décadas. Este fenómeno ha provocado la existencia de distritos periféricos habitado mayoritariamente por la primera y segunda generación de inmigrantes rurales, de muy bajo nivel económico y cultural.

Circunstancias parecidas le ocurre a Tetuán. Ciudad de reivindicaciones autonomistas en la que, a diferencia de la anterior, el conocimiento del idioma castellano no está tan extendido entre las personas jóvenes. Seguramente debido a la afluencia de inmigrantes procedentes de otros lugares de Marruecos.

- Marruecos y el terrorismo yihadista en el periodo 1950-1995:

El derrumbamiento de los imperios coloniales después de la Segunda Guerra Mundial y la llegada al poder de fuertes líderes nacionalistas musulmanes, como Gamal Abdel Nasser en Egipto, determinaron que a comienzos de los años sesenta hubiera ya un cinturón de estados independientes y predominantemente islámicos que se extendían de Marruecos a Indonesia.

El derrocamiento -caso del primer ministro Mossadeq en Irán, en 1953- o el fracaso de los movimientos nacionalistas laicos, atrapados en la vorágine de la guerra fría, tanto en la lucha contra el estado de Israel como en el esfuerzo para el desarrollo económico, con recetas capitalistas o comunistas -igualmente occidentales a ojos de los musulmanes-, terminó convenciendo a importantes sectores de que el Islam era su última oportunidad. Así el Islam se recrea en la búsqueda de la estabilidad y de las raíces, inspirada por un rechazo de los valores occidentales, negando tanto el colonialismo occidental como el comunismo en busca de la espiritualidad y una reafirmación del poder político del Islam, a lo que contribuyó la revolución iraní del ayatolá Jomeini con la expulsión del Sha Reza Pahlevi.
De esta manera, la ideología islamista inunda el mundo musulmán en la década de los sesenta, donde la mayor parte de los países afrontan las consecuencias de grandes cambios sociológicos radicales: la urbanización masiva de gentes procedentes de las áreas rurales, una explosión demográfica y la alfabetización de las clases pobres.

Otros factores, ahora de carácter endógeno e íntimamente ligados a la situación interna del reino alauita en 1960 , como la necesidad de hacer frente al auge de la izquierda más radical, especialmente en los medios intelectuales y universitarios, hacen que el régimen marroquí apoye el nacimiento de una serie de grupos islámicos que comenzarían a disputar a los izquierdistas el control de las universidades.

En esta época surgen asociaciones como el Movimiento de la Juventud Islámica (MJI), fruto de los contactos que mantuvo Sayyed Qotb, líder de los Hermanos Musulmanes de Egipto, con intelectuales marroquíes en el exilio, en busca de una solución a los problemas a través de la sharía y el rechazo de los valores occidentales, adoptando parte del contenido social y revolucionario de la izquierda.

El asesinato, poco claro, del dirigente de la Union Socialiste des Forcer Populaires (USFP), Omar Benjelloun, en 1975, marca la ruptura del régimen marroquí con la organización islamista y la radicalización de ésta, que iniciaría la lucha armada contra el régimen alauí. El grupo por la Libertad, el Movimiento de los Muyahidines de Marruecos, el Grupo de la Yihad o la Juventud de la Revolución Islámica son algunos de los nombres de los grupos más radicales que fueron prácticamente desmantelados por el régimen alauí a partir de 1984, fecha en la que se produce un cambio de estrategia en la política de Marruecos que determina en buena medida la actual configuración del movimiento islamista en esta región.

El nuevo contexto, que provocó la práctica desaparición del MJI, posibilitó que parte de su militancia fuera absorbida por otras formaciones, tras el fracaso de reagrupación como el intentado a través de la creación del Consejo Supremo Islámico para la Guerra Santa.

Los atentados de Casablanca, Nador y Marraquech en 1984, determinan una dura política del régimen orientada al control de las mezquitas, 
la institucionalización del clero y el control de los centros de formación del personal religioso, consiguiendo, hasta 1986, desactivar a los movimientos más radicales, imponiendo una nueva política religiosa donde, como se mencionado anteriormente, el rey ocupa la cúspide.

Es en este contexto, buscando un islamismo moderado, donde los departamentos de filosofía han sido sustituidos por Departamentos de Estudios Islámicos y cuyos licenciados han encontrado un espacio en las cofradías islámicas donde, unidos a los ulemas que fueron apartados de las mezquitas por verter críticas contra el régimen, se empieza, en la década de los 80 , a elaborar un nuevo figh -jurisprudencia islámica- que defiende la idea de un nuevo acceso directo al Corán y a los hadit -sin pasar por la Salafía o tradición pía-, hecho que supone una crítica abierta al salafismo, concepción religiosa dominante en Marruecos ${ }^{9}$.

El actual panorama del fenómeno islamista en Marruecos determina la existencia de organizaciones de tendencia teológica o política. Así, dentro de las primeras -teológicas-, de tendencia sufista, se encuentran:

- Bushishiya.

Sin duda la más importante en Marruecos y centro de paso hacia asociaciones islámicas de carácter político.

- Sociedad para la propagación de la fe. Tabligh wa Daw.

Asociación panislámica de origen pakistaní. Se organiza alrededor de las mezquitas de barrio o pueblo formando a sus miembros en asuntos religiosos y en las técnicas del discurso público y la propaganda. Al igual que la anterior, supone una asociación de paso hacia grupos de carácter más político.

Respecto a las organizaciones políticas, que preconizan el activismo dentro de una dimensión islámica con vistas a transformar la sociedad, se encuentran:

- Justicia y Caridad. Al adl wa Ihsane.

Organización crítica con el gobierno marroquí y el salafismo, estudia la economía

9. El principal ideólogo de esta corriente es el Sheik Yasin, líder del Movimiento Justicia y Caridad. y la jurisprudencia islámica, en las que ha asentado las bases ideológicas de su movimiento. Crítica igualmente con las democracias occidentales por su carácter laico, proclama la creación de una sociedad islámica a través de la Sharía y revolución -modelo iraní-, si bien, en la medida que las democracias sean capaces de ofrecer un espacio al Estado Califal, aceptarían sus principios. Su no cuestionamiento de la legitimidad religiosa del rey permite a esta organización disfrutar de la tolerancia del régimen.

Controlando las universidades y los sindicatos, Justicia y Caridad se ha introducido en los gremios de taxi, enseñanza, sanidad, puertos y pequeños comerciantes y artesanos. Con todo, la principal misión de esta organización supone la labor de implantación que viene haciendo en las zonas más desfavorecidas, donde conjuga el proselitismo con la asistencia social.

- Movimiento Popular Democrático y Constitucional, y la Asociación Unidad y Reforma.

Liderado por Abdalah Benkiran, destacado activista del Movimiento de la Juventud Islámica. Se funda en 1982 como una nueva asociación denominada Asamblea Islámica - Jemaa Islamiya- produciéndose un acercamiento al régimen que culminaría en 1992 con la formación de la Asociación para la Reforma y la Renovación, cuyo ideario refleja la aceptación explícita del los denominados fundamentos sagrados del régimen alauita: el Islam, la integridad territorial y la monarquía constitucional, en la que se incluye el respeto a la legitimidad religiosa del monarca.

Impulsores de la aplicación estricta de la Sharía, el zakat y la obligatoriedad de la lengua árabe en la administración, la enseñanza y los medios de comunicación. Se considera parte de una corriente internacional que lucha, a pesar de su moderación, contra los valores occidentales.

Tal como recoge en la audiencia Nacional en el Auto de Procesamiento del sumario 20/04 (Juzgado Central de Instrucción, 2004:1396), es a principios de los años 90 cuando los veteranos de guerra de Afganistán crearon la corriente Salafia Jihadia, liderada entonces por doce personas entre las que se encontraban Mohamed El Fezzazi, Omar Hadouchi y Zakariya Miloudi desde las ciudades de Tánger, Tetuán y Casablanca respectivamente. 
La corriente de pensamiento que representaban se inspiraba en un salafismo puro, favorecedor del retorno a Marruecos de los muyahidines que habían participado en la yihad internacional. El despliegue de éstos por los barrios más desfavorecidos llevaría al reclutamiento de jóvenes marginales, a los cuales alentaban en la comisión de atentados contra las fuerzas de seguridad, traficantes de drogas y consumidores de alcohol.

Radicalizadora de militantes activistas dispuestos al martirio, la corriente Salafía Jihadia sirvió de inspiración para la creación de las siguientes organizaciones terroristas:

- Grupo Islámico Combatiente Marroquí (Juzgado Central de Instrucción, 2004: 1936 -1937).

Movimiento violento contra el régimen marroquí, sus aliados occidentales y los judíos. Financiado por Al Qaeda, fue fundado en Pakistán en el año 1993, bajo la denominación de H.A.S.M. -Al Haraka Al Islamia Al Maghribia-, e inspirado en el G.I.A. -Grupo Islámico Armado- argelino, presenta entre sus objetivos derrocar al régimen marroquí e instalar un estado islámico.

Formados sus miembros en Irak para el ejercicio de la yihad, se han integrado en organizaciones como Ansar Al Islam / Ansar Al Sunnah, teniendo conexiones con agrupaciones islamistas radicales como $\mathrm{Al}$ Qaeda, Talibán, G.I.C.L. -Grupo Islámico Combatiente Libio-, G.I.A. argelino -Grupo Islámico Armado-, G.S.P.C. -Grupo Salafista para la Predicación y el Combate-, Yihad Islámica Egipcia y Partido Islámico Hikmatiar.

- Al Harak Salafiya Al Jihadiya (Juzgado Central de Instrucción, 2004:1937-1938) -Movimiento Salafista para la Guerra Santa-. Organización radical ideológicamente cercana a Al Qaeda, constituye un conjunto inconexo de islamistas con su líder espiritual en el imán Mohamed Abdelouahab Rafiki -alias Abou Hafs- instalado en la mezquita de Sale (Marruecos).

Tras la invasión de la isla Perejil se pronuncian a favor de la yihad contra España para la recuperación de las ciudades de Ceuta y Melilla y la Comunidad Canaria.

- Jammat As Sirat Al Mustaquin -Comunidad del Camino Recto- (Juzgado Central de Instrucción,
2004:1398). Organización a la que se atribuyen los atentados de Casablanca el 16 de mayo de 2003, entre los que se cuenta el perpetrado contra la Casa de España, fue fundada por antiguos muyahidines marroquíes, los cuales tuvieron un entrenamiento en los campos habilitados por Al Qaeda.

Presenta una actividad especialmente intensa en los barrios populares de Casablanca realizando labores de reclutamiento de nuevos adeptos.

- Influencia de la fecha y lugar de nacimiento en la adaptabilidad social en Marruecos.

Desde 1974 y durante veinticinco años hasta 1999-, periodo cuando nacen y forman su personalidad los terroristas investigados, Marruecos tuvo como ministro de Asuntos Religiosos a Abdelkebir M"Daghri Alaoui (Arístegui, 2005:291), de ideas muy próximas a los planteamientos de los Hermanos Musulmanes, de actitud laxa a los planteamientos radicales y permisivo con los sermones que circulaban en cinta de casete, el cual introdujo en las escuelas libros de texto ultra conservadores y rigoristas.

En este mismo periodo, con la intención de aumentar el control sobre la formación de líderes religiosos, se crea -año 1979- la licenciatura de Estudios Islámicos (Pérez González, 2004), cuyo fracaso genera un numeroso grupo de licenciados cuya única salida es el paro. Sin trabajo y habiéndose educado con libros radicales, permitidos por el citado ministro M"Daghri, inspirados por los Hermanos Musulmanes en tendencias rigoristas dentro del salafismo, los jóvenes así formados son fácilmente captados para el radicalismo, fruto del creciente wahabismo, del paro al que se han visto abocados y de trabajos mal remunerados, situación que determina un estado de frustración de estos sujetos contra el sistema.

El estado de frustración, el paro, la permisividad, la proliferación de mensajes radicales $\mathrm{y}$ el aumento del número de predicadores a favor de la yihad alientan a los jóvenes marroquíes a unirse a las batallas de Kosovo, Bosnia, Afganistán o Irak. Del avance del islamismo radical se hace eco el PEW Center for the People and the Press de marzo de 2004, que refleja el $45 \%$ de apoyo marroquí a Osama Bin Laden y el $60 \%$ de apoyo a los atentados suicidas en Irak (Arístegui, 2005:296). 
La propagación del radicalismo islamista en Marruecos por medio del salafismo ${ }^{10}$ a través de $\mathrm{Al}$ Qaeda y por la red del Grupo Islámico Combatiente Marroquí, unido a la concentración en Marruecos de "los afganos"11 cuya dedicación a la pequeña delincuencia supone su forma de vida, hace que sean éstos el objetivo prioritario de reclutamiento para el terrorismo yihadista por parte de aquellos otros formados en asuntos religiosos; frustrados, en el paro y ya radicalizados.

En este contexto resurge el islamismo en tres grupos sociales bien distintos:

El primer grupo está integrado por la juventud pobre y urbana, que, según qué países, representa entre el cuarenta y el sesenta y cinco por ciento de la población; son jóvenes frustrados, sin empleo y que no han conocido la colonización, lo que hace que centren su ira en el Estado postcolonial que no ha sabido resolver sus problemas -Argelia a partir de 1988-.

El segundo grupo supone una pequeña burguesía islamista emergente pero que no tiene acceso al sistema político, tanto en los países que se dicen socialistas, donde el poder pertenece por lo general a los militares, como en los países monárquicos, donde son unas pocas familias las que disfrutan del poder. Esta pequeña burguesía, integrada por comerciantes o pequeños empresarios, no es revolucionaria, pero quiere desbancar a los que ocupan el poder. No descenderá a la calle, pero financiará un movimiento político que fundamentalmente se apoyará en los desheredados.

El tercer grupo será el que proporcione la ideología islamista. Jóvenes formados en las universidades estatales y que, a la vista del fracaso de las recetas occidentales, optarán por convertirse en creadores del estado islámico, al que consideran perfecto.

Que en 1998 Bin Laden y Al Qaeda se conviertan en la organización de referencia del movimiento árabe-afgano y en máximos representantes de la ideología salafista, unido

10. Derivado esencialmente del wahabismo, que es a su vez una interpretación de las más rigoristas de la escuela jurídica suní, la hanbalí.

11. Veteranos de la guerra de Afganistán. a la declaración de yihad contra los Estados Unidos y sus aliados -23 de febrero de 1998estableciendo regímenes islamistas salafistas en la Umma, hace que aquellos sujetos de los que venimos haciendo referencia, integrados en un ambiente social como el descrito, influenciados por unos actores educados en un contexto convulso, de crisis, de expectativas frustradas de avance social, con ruptura de progresos sociales, en paro, subsistiendo mediante el uso profesional de la pequeña delincuencia, altamente deprivados y conscientes de dicha privación relativa, les posiciona en una situación de difícil adaptación social, tanto en su lugar de origen como en los lugares a que pudiera emigrar, toda vez que la mencionada relatividad de adquirir un estado de bienestar adecuado les llevaría a un mayor grado de frustración y en consecuencia a una mayor rebeldía, incluso insurgente, pretendiendo modificar el statu quo a su favor.

Los trastornos de conducta, resultado de la disfunción para enfrentarse a las dificultades de la vida, lleva al sujeto a reproducir miméticamente estados de frustración aprendidos mediante la educación y el control paterno (Lila, 2004:5257), el cual, como anteriormente observamos, en nuestra investigación se corresponde con una alta demanda religiosa.

Por estos motivos, especialmente la frustración paterna, precisamente del agente socializador, el sujeto madurará en un proceso de bajo control y con ausencia del factor afectivo de la madre, cuyo resultado obra a favor de la clasificación de Henggeler (1989) que dispone, para estos supuestos, sujetos con graves déficit en su desarrollo social y con problemas para la interacción humana. Factores de clara tendencia en la generación de jóvenes delincuentes, tanto más para aquellos que emigren a otras culturas que para aquellos otros que viviendo en su lugar de nacimiento tienen interiorizados los valores y normas sociales de origen.

Por otro lado, la relación de los lugares de nacimiento de mayor frecuencia -Tánger y Tetuán- y el proceso de maduración de los individuos nacidos especialmente entre los años 1973 y 1979, supone una influencia del agente socializador con tendencia independentista, al vivir éste procesos como la invasión del Sahara Occidental -1975-, desoyendo los deseos de los saharaui y posteriormente las resoluciones 
de Naciones Unidas, a lo que se une el mismo carácter independentista de la ciudad de Tetuán y la especial situación de Tánger.

Con un trasfondo de guerras en áreas de culturas similares -Siria, Israel, Egipto, Palestinael abandono en 1985 por parte de Marruecos de la Organización de la Unidad Africana, el ofrecimiento de una visión posibilista de cambiar el entorno -toma del poder en Afganistán por los talibanes-, la guerra de Kosovo -1999- y la idea expansionista que ofrece la yihad islámica, hace que los sujetos pugnen contra aquellos estados que vienen considerando el eje del mal -Estados Unidos e Inglaterra, especialmente- así como aquellos otros, colaboradores de éstos, a los que observan cada vez más fuertes y unidos -moneda única europea, 1998 a 2001-.

Entendemos que son todos estos considerandos los que llevan a ofrecer, en los terroristas investigados, un alto porcentaje de sujetos fanatizadores, que representan un liderazgo, con dificultades para integrarse tanto en su cultura como en otras diferentes.

- Aspectos socio-culturales de Siria y procesos de socialización (en línea, Tarij, 2000; Laguia, 2000: Blogia, 2005)

La República Árabe Siria, situada en Oriente Medio, presenta fronteras al norte con Turquía, al este con Irak, al sur con Jordania y al oeste con Líbano, Israel y el mar Mediterráneo. Con población que practica mayoritariamente la rama suní del Islam, cuenta, desde el año 1919, con la existencia, en la ciudad de Damasco, de la Academia Árabe, dedicada al estudio de la lengua, la literatura, la historia y la cultura árabe. Otra población como Homs, recibe un especial interés para nuestro estudio, en la medida que en ellas se concentran un mayor número de habitantes y los principales centros de culto, tal como se verá más adelante, así como las características y peculiaridades de las mismas y su posible relación causal con dos de los sujeto investigados -D, L-. Otra ciudad, Aleppo, será tenida en cuenta, en la fase de pronóstico, dado el alto carácter religioso que ofrece.

Previo a las reflexiones que se harán respecto a la influencia religiosa en Siria, se precisa de una ubicación contextual, al objeto de poder entrever el modo en que algunas organizaciones terroristas, como los Hermanos Musulmanes, pudieran participar de la construcción idiosincrásica de la población.

Sin necesidad de profundizar en la historia de Siria más allá de principios del siglo XX, se observa cómo, a raíz del final de la Primera Guerra Mundial, el imperio Otomano, que dominaba Siria, se disuelve y permite el ejercicio del poder a Francia, como consecuencia del reparto efectuado por la Liga de las Naciones -año 1922-, propiciándose, veinticuatro años después -año 1946-, tras algunos intentos independentistas sirios, no reconocidos por Francia -años 1936, 1941-, y como consecuencia de las presiones de los grupos nacionalistas sirios y la presión británica, la instauración de un régimen político republicano independiente -1 de enero de 1944-, sin la ocupación de las tropas francesas, evacuadas en abril de 1946.

A pesar del rápido desarrollo económico que siguió a la declaración de independencia, la política siria estuvo marcada por vaivenes hasta los últimos años de la década del 60, así, entre los años 1946 y 1956, participó de veinte gobiernos diferentes y redactó cuatro constituciones.

La participación siria en la guerra árabe-israelí -año 1948- desencadenó una serie de golpes militares -años 1949, 1951, 1954- que minaron los distintos gobiernos civiles que se encontraban establecidos, llevando a elementos nacionalistas y socialistas árabes al poder.

La declaración en el año 1956 de la ley marcial en Siria, durante la crisis de Suez, en la que intervinieron militarmente británicos y franceses, determinó que tropas sirias e iraquíes se trasladaran a Jordania, asesorando estos últimos a Egipto y Siria contra una concebible toma de posesión de su territorio, a fin de prevenir una posible invasión israelita,.

La inestabilidad política de Siria durante los años después del golpe de 1954, armada militarmente por un pacto firmado en 1956 con la Unión Soviética, el paralelismo de las políticas sirias y egipcias, y la atracción del liderazgo del presidente egipcio Gamal Abdel Nasser en el inicio de la crisis de Suez, crearon el apoyo en Siria para la unión con Egipto, anunciando la fusión de ambos países, configurando, con poco éxito, la República Árabe Unida -año 1958-, que sucumbió, 
en 1961, ante un nuevo establecimiento de la República Árabe Siria.

La continua inestabilidad política de Siria, con sucesivos golpes de estado militar, posibilitaron que los Altos del Golán, región independiente de Siria tras el mandato francés ejercido sobre la zona una vez terminada la I Guerra Mundial, y de elevado valor estratégico, tanto militar, dominando la ciudad de Damasco y la llanura sur de Siria hacia el norte y el este, como por los nacimientos de agua dulce -lago Tiberíadesque supone una importante fuente de ingresos para Israel, fuera invadido por este último, precipitando la Guerra de los Seis Días de 1967, donde los árabes de Siria y Jordania, liderados por Egipto, fueron derrotados.

Posteriormente, consecuencia del persistente conflicto árabe-israelí por el control de la región de la Palestina histórica -guerras en 1948, 1956 y 1967-, a pesar de las solicitudes de distensión que la Unión Soviética hacia a Egipto para pacificar la zona, éste, tras visitar su dirigente Sadat a Siria, cuyo interés no era sólo fruto del panarabismo, sino que seguía recibiendo suministros soviéticos de armas en gran cantidad, mientras que Egipto, tras desoír a la Unión Soviética, tenía una limitada capacidad para renovar su material militar, acordaron el ataque, mediante la operación denominada Operación Badr (Luna Llena), a los Altos del Golán, el 6 de octubre de 1973, día de Yom Kippur, fiesta judía, durante la que previsiblemente la mayoría de la población se encontraría en las sinagogas y los soldados descuidados o de vacaciones, aprovechando, igualmente, la connotación simbólica que este día ofrece a los musulmanes, dado que para su calendario, en dicha fecha, Mahoma decidió entablar la Batalla de Bard que le dio la primera victoria musulmana contra los infieles de la tribu de Quraish.

A pesar de la guerra en la que el ejército israelí sufrió numerosas bajas, éste derrotó a las tropas árabes e invadió más territorios pertenecientes a Egipto y Siria, zonas que, tras el acuerdo diplomático de 1975, por el que se establecía la existencia de una zona neutral custodiada por la fuerzas de las Naciones Unidas, que se extendía al este del canal de Suez y sobre el territorio del Golán, posibilitó, con la mediación de los Estados Unidos, un tratado de paz -17 de septiembre de 1978- por el que los egipcios recuperaron territorios -Sinaí- y se decidió la libre navegación del Canal de Suez, determinando como objeto de negociación, para el establecimiento de un régimen autónomo, la franja de Gaza y Cisjordania.

A pesar de ello, los continuos ataques palestinos, que no estuvieron de acuerdo con la paz, y que terminaron con la vida del pacifista árabe Sadat, tuvieron como respuesta que los israelíes invadieran el sur de Líbano -año 1981y se anexionasen los Altos del Golán, extendiendo la Ley Civil israelí a toda la región, acciones que Siria, al igual que la mayoría de los demás países árabes, se han negado a reconocer.

Tras estos acontecimientos Egipto, que había sufrido derrotas como la del año 1956 donde, con motivo de la nacionalización de la Compañía del Canal de Suez, se enfrentó a fuerzas conjuntas francesas, británicas e israelíes, restablecía cierto equilibrio simbólico con Israel, facilitando así su alejamiento de la tesis soviética y el acercamiento a los Estados Unidos, mientras que Siria mantuvo su vinculación con la URSS, favoreciendo, de esta manera, la aproximación de Egipto al mundo occidental y la posibilidad de distintos acuerdos que culminaron con el de Camp David.

Durante gran parte del tiempo referido, determinado por alianzas y tratados entre Egipto y Siria, el sentimiento de transición es tan fuerte que algunos predicadores luchan por la identidad de Siria en esferas donde el estado tiene poco que decir. Así, los fieles trazan la frontera entre ellos y el gobierno Baazista, que llegó al poder, décadas atrás, en nombre del nacionalismo árabe secular, imponiendo manifestaciones $\mathrm{y}$ expresiones religiosas, determinando que cada vez más sirios se acerquen a las mezquitas.

De esta manera, la Hermandad Musulmana, que durante décadas ha sido una de las más visibles del activismo musulmán en Siria, realiza su proselitismo religioso, en la mezquita de Abu Nour, en la ciudad de Damasco, facilitando versiones en distintos idiomas, entre ellos el español, del discurso Gran Muftí, homilía sobre la interpretación del conocimiento del Islam e impulsando la creciente religiosidad de la sociedad siria, orientada a las donaciones y tolerada por un gobierno ostensiblemente laico.

Este reconocimiento religioso, que lleva ya una generación remodelando Siria, en manos de los Hermandad Musulmana, que cuenta con 
acceso tanto a dinero como a los medios de comunicación, y con especial apego entre los sunnís -que constituyen la mayoría en Siria-, fue objeto de sangrientos enfrentamientos con el gobierno -de tendencia alauita, una versión del Islam chií- a finales de los años setenta y principio de los ochenta, siendo miles de partidarios de la Hermandad muertos o encarcelados, y sus dirigentes obligados a exiliarse. Así, desde Siria, la oposición al gobierno viene llamando a acercarse a la Hermandad como un modo de favorecer sus posiciones, potenciando luchas entre fuerzas seculares y religiosas, entre el gobierno $\mathrm{y}$ figuras de la oposición y, en la mezquita de Abu Nour - Damasco- y otros lugares, entre el clero, respaldado por el gobierno, y una tendencia más radical mantenida a flote por la guerra de Irak.

A pesar del mensaje de pluralismo religioso que algunos miembros del parlamento sirio, como Habash, director del Centro de Estudios Islámicos, evoca, organizando foros y coordinando grupos de estudios, así como leyendo sermones diarios en radios privadas, parece relevante determinar la influencia que ha ejercido, y ejerce en la actualidad, sobre la población Siria, las tesis de la Hermandad Musulmana.

\subsection{Rasgos criminógenos}

Las tendencias y dispersiones que han ido dirigiendo la investigación permiten confeccionar el gráfico 9 (en anexo, p. 208), capaz de sintetizar aspectos, a nuestro entender relevantes, de los terroristas yihadistas participantes en el atentado perpetrado en Madrid el 11 de marzo de 2004.

Rasgos como liderazgo, fanatizador, año y lugar de nacimiento o la participación en actividades de delincuencia común, han de ponerse en relación más allá de un gráfico, de manera que su estudio de causalidad nos informe de las contingencias de los datos.

Los gráficos 10 y 11(p.p. 208 y 209) adicionan los rasgos tratados en torno al de fanatizador, ya que entendemos que será éste sujeto el que reúna la mayoría de las características radicales, así como que aportará al grupo la identidad colectiva en la que la violencia represente un componente primordial. Las redes sociales familiares o de amistad facilitarán la atracción entre los elementos integrantes de la subcultura que gira, en la mayoría de los procesos, alrededor del líder-fanatizador, cuya unión de rasgos determina en gran medida el nivel de radicalización.

La elevada socialización subcultural que presentan los sujetos fanatizadores les lleva a atraer con cierta facilidad a individuos inadaptados, presumiblemente inmaduros y psicológicamente frágiles, lo cual nos orienta en dos tipos de conductas claramente desadaptativas a la hora de la adaptabilidad social: agresión e inmadurez.

Si el rasgo 12 "agresivo" del que participan todos los sujetos estudiados (Aud. Nal., JCI no6, E.S. 20/04: Carpeta 11; Sala de los Penal, Sentencia 20/04) les hace ser combativos, belicosos, desafiantes de la autoridad y hostiles, claramente objetivables en los datos aportados, la inmadurez de los sujetos fanatizados no queda constatada, en la medida que este trastorno participa de unas características específicas como la pasividad -que no se da-, escasa capacidad de concentración -sin constatar-, torpeza, tendencia a la ensoñación o falta de compromiso (Aud. Nal., JCI no, E.S. 20/04: Carpeta 11; Sala de los Penal, Sentencia 20/04), nos hacen prever que estos individuos han progresado efectivamente en su madurez social, si bien, en la sociedad subcultural.

Así, de la información aportada por los distintos órganos de la Administración de Justicia, a la que se viene haciendo referencia, se puede colegir que las personalidades configuradas por estos terroristas presentarán agresividad, pero no síntomas de inmadurez o retraimiento.

De esta manera, no presentarán déficit en: habilidades sociales -mantener una conversación, integrarse en grupos-; habilidades afectivas resolver el miedo, expresar afecto, comprender los sentimientos de los demás-; habilidades para afrontar el estrés -solucionar problemas o tomar decisiones, enfrentarse al fracaso-y en habilidades de autocontrol - manejo de la propia agresividad, enfrentarse a las presiones del grupo-.

12. Al nutrirse la presente investigación de diferentes fuentes ha parecido pertinente acomodarse, para el estudio de la Adaptabilidad Social, a los rasgos aportados por la fiscalía y el Tribunal Sentenciador, al entenderse que los mismos proceden de fuentes solventes y no se encuentran sujetos a que pudieran provenir de un cierto hospitalismo, como es el caso de los aportados por Instituciones Penitenciarias. 
El gráfico 12 (en anexo, p. 209) ofrece la visión del conjunto de datos criminógenos tratados preferentemente, informando de la relevante tendencia a la inadaptación social -en la cultura occidental- de los sujetos del censo.

De la interpretación de las tablas se colige la elevada implicación de los terroristas fanatizadores y no fanatizadores que participan en otras actividades terroristas, especialmente si han realizado otros actos delictivos. Siendo trascendente la distancia que les separa con aquellos que no han participado en otras actividades terroristas.

La tendencia al terrorismo de los sujetos nacidos en Tetuán o Tánger, fanatizadores, y con la existencia de otros que reuniendo las mismas características hayan nacido el mismo año, se observa determinante, frente a aquellos que cumpliendo los mismos requisitos no hayan nacido en las ciudades referidas, luego, el lugar de nacimiento se resuelve como significativo, si bien, sólo para los fanatizadores, ya que los no fanatizadores presentan una mayor tendencia al terrorismo precisamente si no han nacido en éstas ciudades.

Siguiendo a Göppinger, el rasgo fanatizador, que comprende el 55,5\% del censo estudiado, nos va a determinar la tendencia inadaptativa de dichos sujetos, toda vez que "las personalidades fanáticas están dominadas por complejos supervalorados de pensamientos personales o ideales", lo que les "aparta de la realidad (...) y se preocupan poco del Derecho y de la Ley" (1975:176) entendiéndose, en este caso, del Derecho occidental, no el de su subcultura.

La pertenencia de todos ellos a la organización Al Qaeda se ha de poner en relación con el tiempo que objetivamente llevan postulando, así, participan de la organización terrorista, de manera que se haya podido demostrar, desde hacía relativamente poco tiempo, viniendo al más antiguo del año 1999.

Los escasos cambios de residencia y trabajo -de los que se tiene constancia- nos hace inferir que el proceso mediante el cual llegó a contactar con el resto de los sujetos de igual clase fue corto, que su acogimiento en el grupo se realizó sin dificultades y que, por tanto, todos ellos participaban de iguales valores, lo que les llevó a fijar su residencia.
Otros rasgos comunes a todos ellos, extraídos de la información que aporta la Audiencia Nacional en sus diferentes salas (Sumario 20/04; Sentencia 20/04), como las creencias encapsuladoras, religiosidad y su tendencia -sunnitas wahabitas de jurisprudencia hanbalí-, conduce a determinar el posicionamiento que ofrecen frente al régimen Alauí, circunstancia que apoya conclusiones más arriba inferidas. Del mismo modo, rasgos como la ansiedad, relacionada directamente con las ideas obsesivas de las que participan como miembros de un grupo subcultural, así como sus ritos y metas, demuestran su grado de socialización desviada y subcultural.

Que no presenten retraimiento social ni aislamiento, así como que tengan capacidad de mantener una conversación e integrarse en grupo, abunda en su capacidad de adaptabilidad social en el grupo desviado, lo que a su vez informa de su alto grado de desadaptación para otros tipos de sociedades, en nuestro interés la occidental.

A su vez, los rasgos de inmadurez, como la transferencia de culpa de sus actos y el egocentrismo, no relacionan correctamente con rasgos como tener capacidad de compromiso (Sumario 20/04; Sentencia 20/04). Interpretación que se ha de dar en el sentido de las razones que venimos observando, es decir, adaptación fanática a su endogrupo e inadaptación social.

La conducta criminal de otros miembros de la fratría ha podido suponer parte de la causa de desadaptación, como consecuencia de mimetismos a agentes socializadores de los que han recibido influencia.

\section{CONCLUSIONES}

\section{Rango}

Adaptabilidad social del terrorista yihadista autor o colaborador en el atentado ocurrido en Madrid el 11 de marzo de 2004.

\section{Resumen}

El estudio de la adaptabilidad social que se ha realizado supone la investigación sectorial, del análisis completo, del perfil de peligrosidad criminal de los terroristas yihadistas condenados por el atentado perpetrado en Madrid el 11 de marzo de 2004. 
Los factores endógenos y exógenos que se han tenido en consideración se entienden suficientes para el ejercicio de valoraciones y conclusiones. Así, los factores biológicos, los procesos de socialización y las dinámicas de grupos, informan del grado y disposición de estos sujetos para integrarse socialmente.

Como se ha podido observar a lo largo del texto precedente, las conclusiones que aproximen al conocimiento socio-cultural del terrorista que nos interesa nos van a ayudar a prever, dentro del pronóstico social-criminológico, el elemento estudiado; la adaptabilidad social. No obstante, las reflexiones que se muestren y el juicio de valor emitido, como ya se expuso en otro momento, han de entenderse en términos de hipótesis, con las reservas que explican los límites del determinismo psicológico imposible de estimar.

Los estudios no concluyentes entre los factores biológico-genéticos y la agresividad (Laqueur, 2003:31), nos inclinan a pensar que "el terrorista se hace en un contexto y a través de una formación..." (Algora, 2005:122). No obstante, no nos parece oportuna dicha aseveración, expresada con tal contundencia, en la medida que participamos de considerar que la agresividad viene modulada por factores endógenos, si bien, el aprendizaje social puede ser considerado como el factor determinante de la conducta agresiva.

\section{Conclusión}

Las hipótesis planteadas y las conclusiones que se han ido obteniendo sobre las mismas en el desarrollo de la investigación, nos permite concluir con una rotunda afirmación a la práctica totalidad de las referidas a la adaptabilidad social, con la excepción de aquella no concluyente que se obtiene de plantear si el terrorista objeto parte de una agresividad innata.

Se ha visto cómo la aplicación de los modelos psico-cultural y social para explicar la delincuencia terrorista han resultado pertinentes, demostrando que aquella parte del constructo de personalidad criminal que afecta a la adaptación social requiere escaso referente a aspectos psicológicos, jugando un papel principal el proceso de socialización subcultural vivido por el sujeto.

A su vez, la determinante inmersión subcultural del individuo, proveniente de una dinámica educacional religiosa impuesta por los grupos primarios de socialización, en una comunidad patriarcal, donde el padre determina en el varón valores como aspectos viriles, el orden, la justicia y la competición, y la madre participa en escasa medida en la formación de los valores ${ }^{13}$ de la fratría, con las consecuencias de un déficit en aspectos afectivos (Göppinger, 1975:179) ${ }^{14}$, hacen que el modelo referido al control paternal determine un sujeto con escasas posibilidades de adaptación social fuera del contexto en el que predominan los valores adquiridos.

De esta manera, aquellos que por diversas razones -no sólo en el ejercicio de la yihaddeciden emigrar a otros países de cultura diferente a la islámica, consideramos que lo hacen con la intención de regresar a ella en cualquier momento $\mathrm{y}$, por consiguiente, con frecuencia se sienten solo como huéspedes (Losada y Bayt, 1993:4) y no como un grupo de población que necesite por tiempo indeterminado estar en buenas relaciones con el conjunto de la sociedad.

Que estén predominantemente de manera legal en España no muestra más que la capacidad adaptativa o disimulo -taqiya- para garantizarse la realización de sus fines, o simplemente el instrumento necesario para poder asentarse en un territorio que le permita llevar a cabo sus actividades de delincuencia común. De ahí, la carga de prejuicios hacia los ciudadanos que han de acogerles, con los que no les une nada más allá de disfrutar del mismo espacio durante un tiempo determinado.

Visto con esta perspectiva, que los sujetos estudiados participen en actividades de delincuencia común presenta sentido si además, estos mismos sujetos, no han adquirido capacidades profesionales que les permita una adecuada integración.

El paradigma del que se ha partido ha permitido que el diseño de la investigación verifique la relación causal entre la religión, cultura, educación y formación profesional, con la adaptabilidad social, así como la relativamente poca influencia de las variables extrañas y la covarianza que se pudiera dar entre ellas. La criminalidad de estos

13. Entiéndase los valores no correlacionados con la religión islámica.

14. Entiéndase nuevamente estos aspectos como aquéllos no derivados de la imposición cultural islámica, basada en una estructura patriarcal. 
sujetos ha sido aprendida en un proceso de socialización deficiente mediante la interacción con grupos primarios que además, influyen en la inclinación delictiva, alentando y formando en la radicalización, mediante modelos y pautas que pretenden hacer del individuo fanatizado el vehículo para conseguir conquistar un espacio social y, a ser posible, conquistar el poder político para definir, de acuerdo a sus intereses, la jerarquía oficial de sus valores subculturales, cuya minoritaria conciencia colectiva, respecto a la yihad menor y el uso de la violencia, les posiciona, incuestionablemente, con carencias respecto a la capacidad para adaptarse socialmente, así como fracaso en la adaptación social.
El método científico seguido para llegar a la conclusión sobre la adaptabilidad, ha permitido detectar la existencia del problema social, discriminar aspectos esenciales, reunir datos, elaborar y contestar hipótesis. Del mismo modo, dado que el número de observaciones es relativamente escaso $-|13|-$, la investigación no ha supuesto una mera actividad de recopilación de datos, ha supuesto, por el contrario, una actividad que genera teorías, dejando espacio a otros diagnósticos y a la revisión de la presente conclusión. 


\section{GRÁFICOS}

\section{GRÁFICO 1}

ACUMULADO POR SEXOS
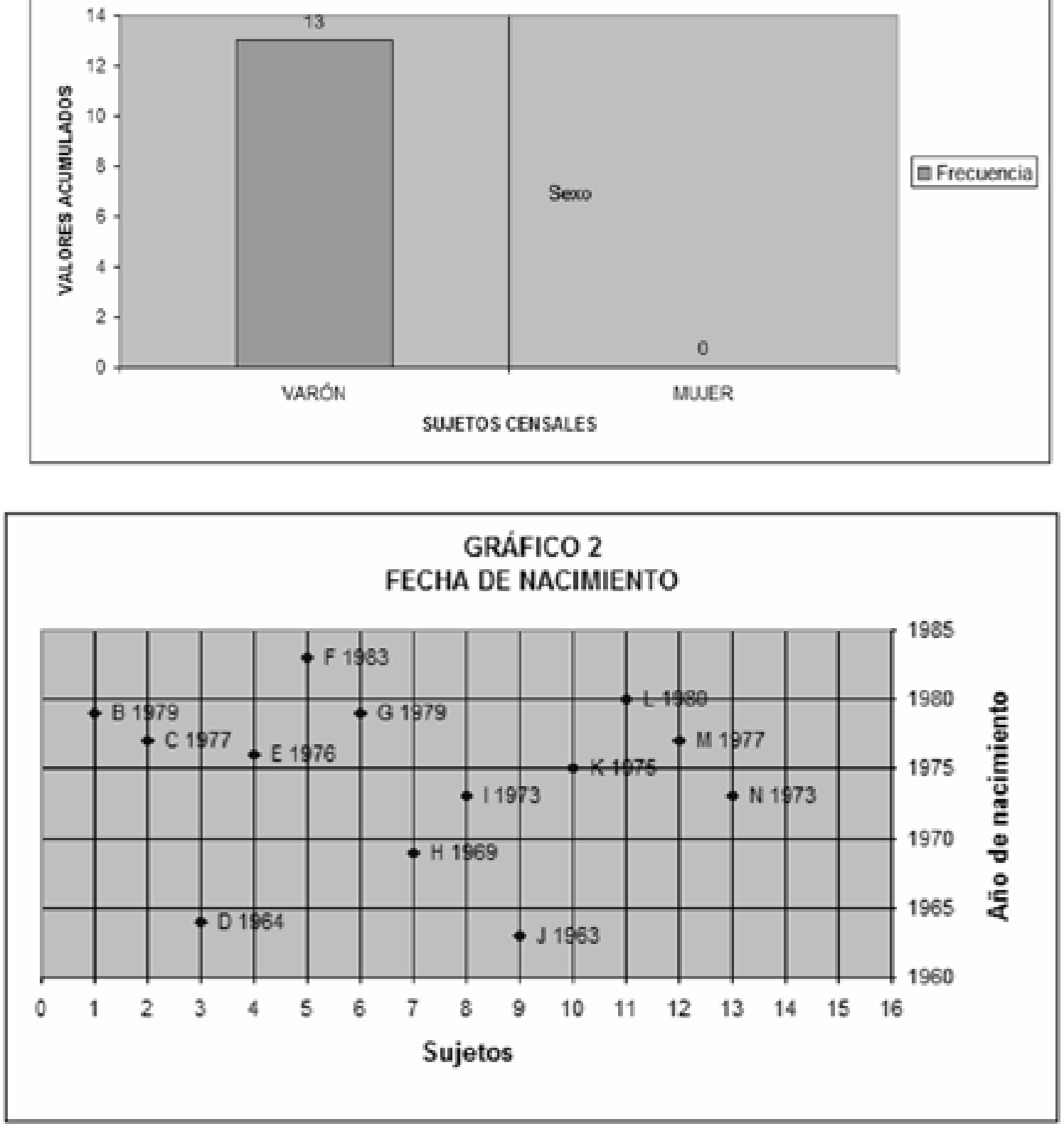

Respecto a la fecha de nacimiento el rango se presenta especialmente amplio - 20 años- , si bien, dada la acumulación de frecuencias, un periodo de cinco años va a suponer el nacimiento del 53,8 \% del censo -gráficos 2 y 3 -. 


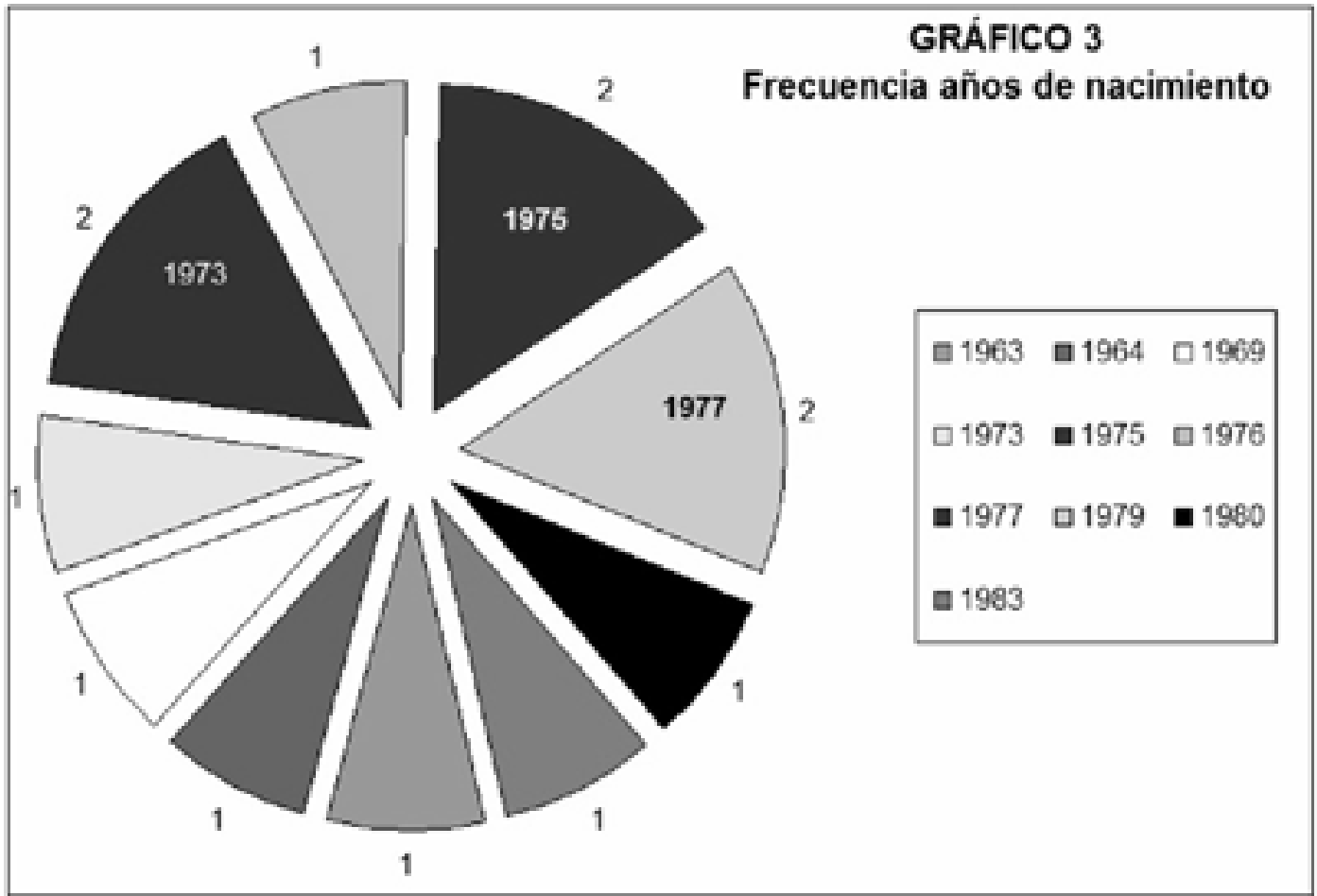

Los gráficos 4 y 5 muestran el país y la localidad de nacimiento observando el peso que, sobre la población estudiada, representa haber nacido en las ciudades marroquíes de Tánger o Tetuán.

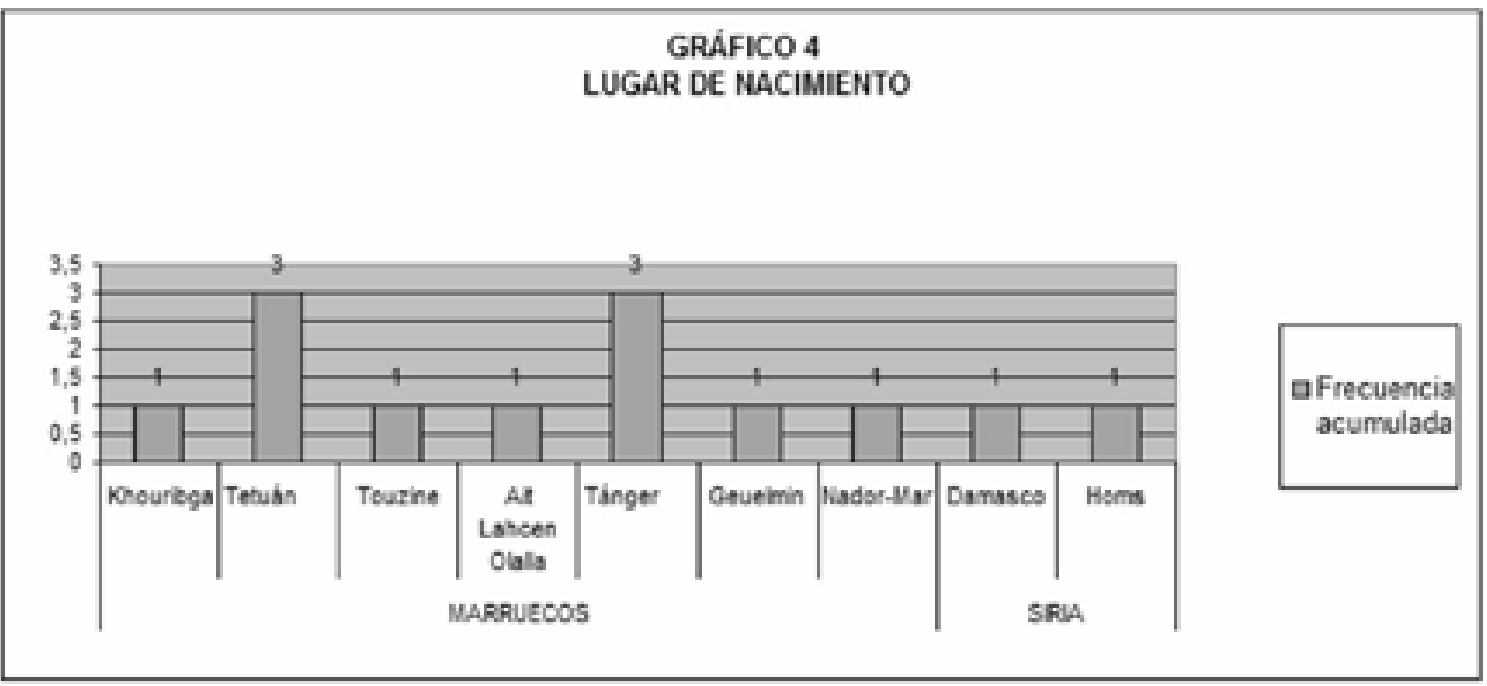




\section{GRÁFICO 5 \\ PAIS DE NACIMIENTO}

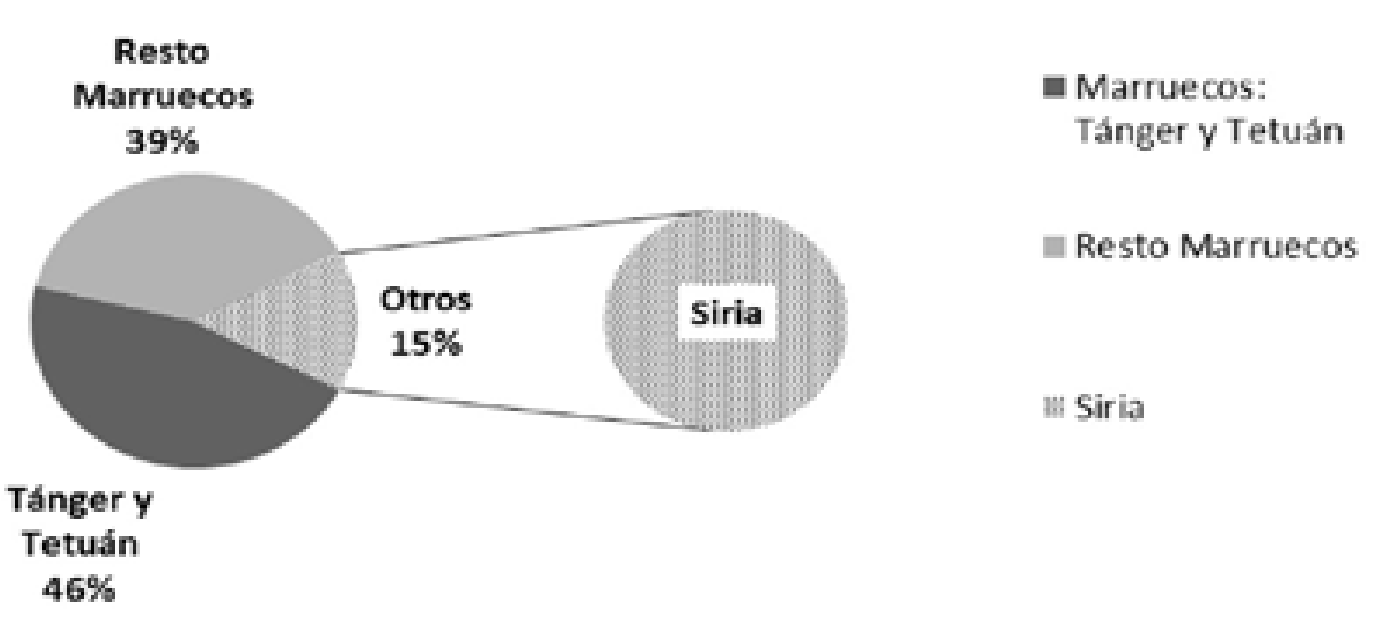

La edad de la detención presenta un recorrido amplio con tendencia modal a la edad de 29 años, con una baja dispersión y una marca de clase de 28 años en el intervalo |25-31|, en el cual se agrupa el 61,5 $\%$ de los sujetos. El peso se refleja en los valores $|25|$ y |29|, cuyas edades suponen una agrupación del $38.4 \%$ de los sujetos estudiados.

Los gráficos 6, 7 y 8 ofrecen una representación visual de tendencias y dispersiones.

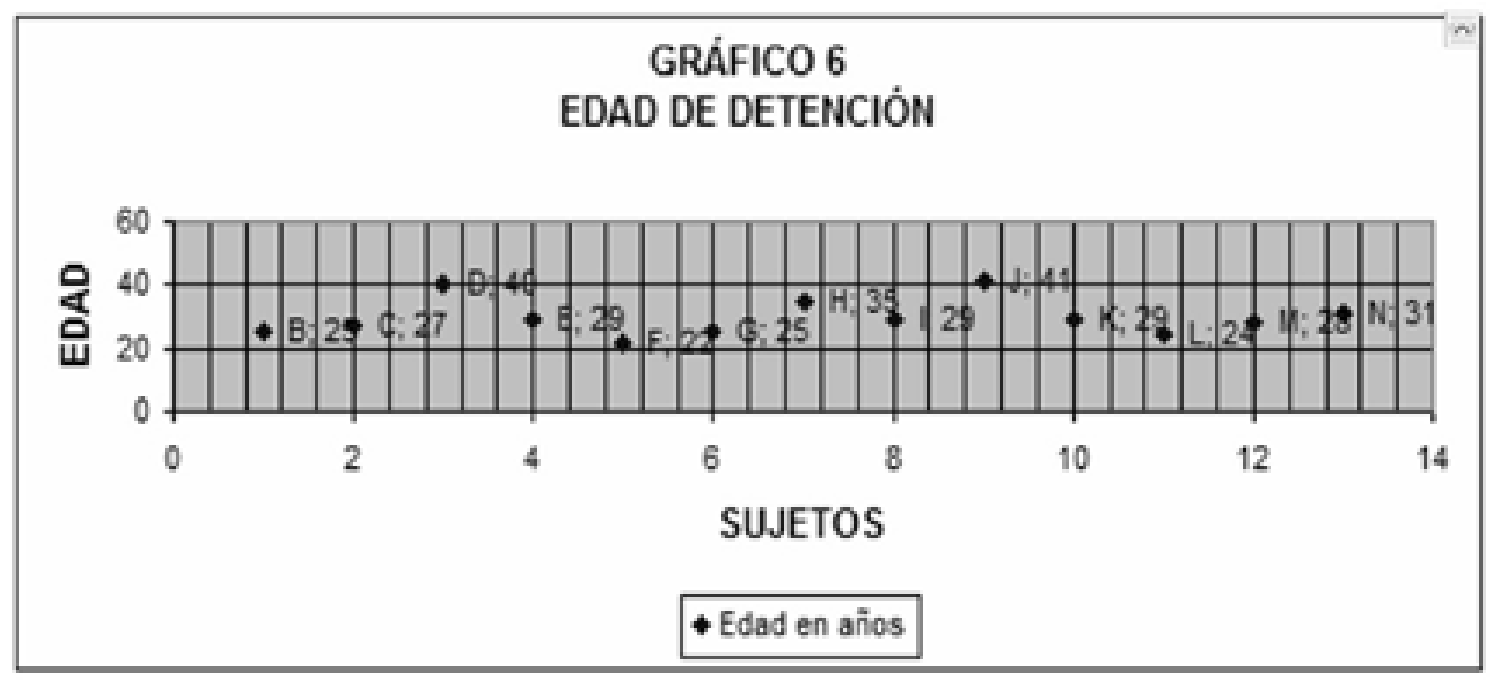



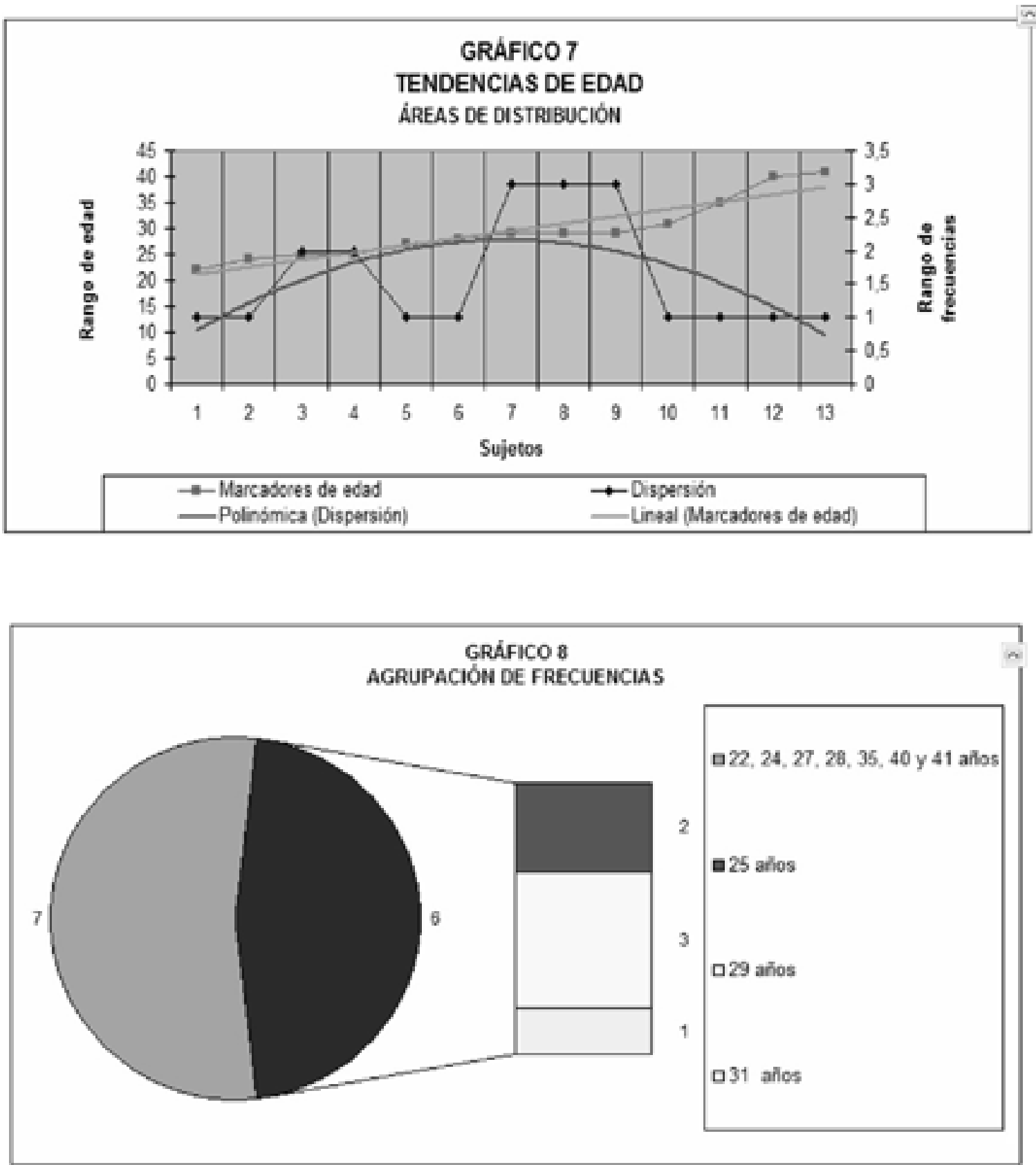

Los rasgos comunes de igual tendencia pueden observarse en los documentos anexos que se acompaña. En otro sentido, los rasgos variables de interés criminógeno, los datos y la actitud de los sujetos en su endogrupo presenta la dispersión observada en el gráfico 9. La adición cuantitativa de los rasgos en cada sujeto ofrece una visión general para el posterior estudio cualitativo de la tendencia criminógena -gráficos 10, 11 y 12 - 


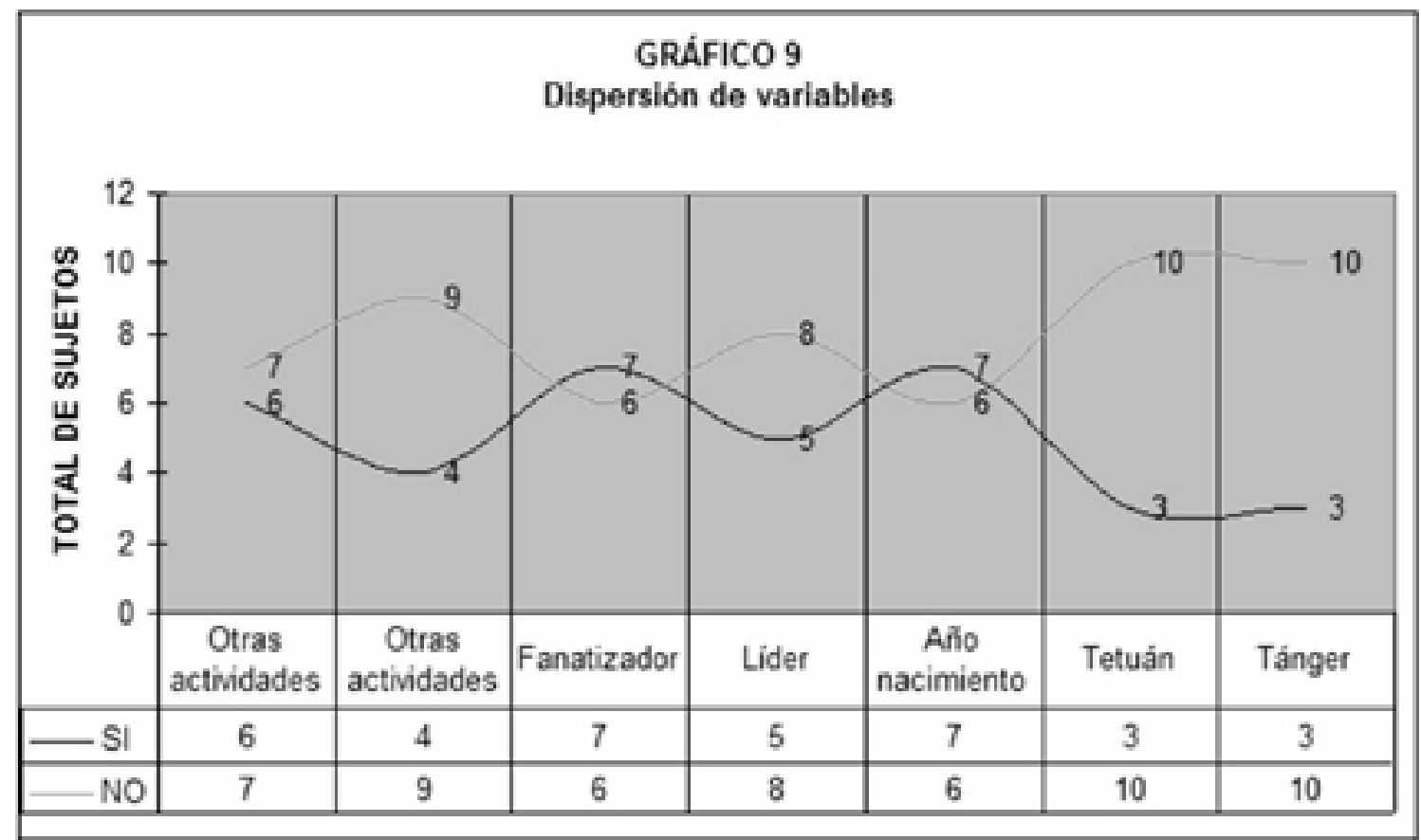

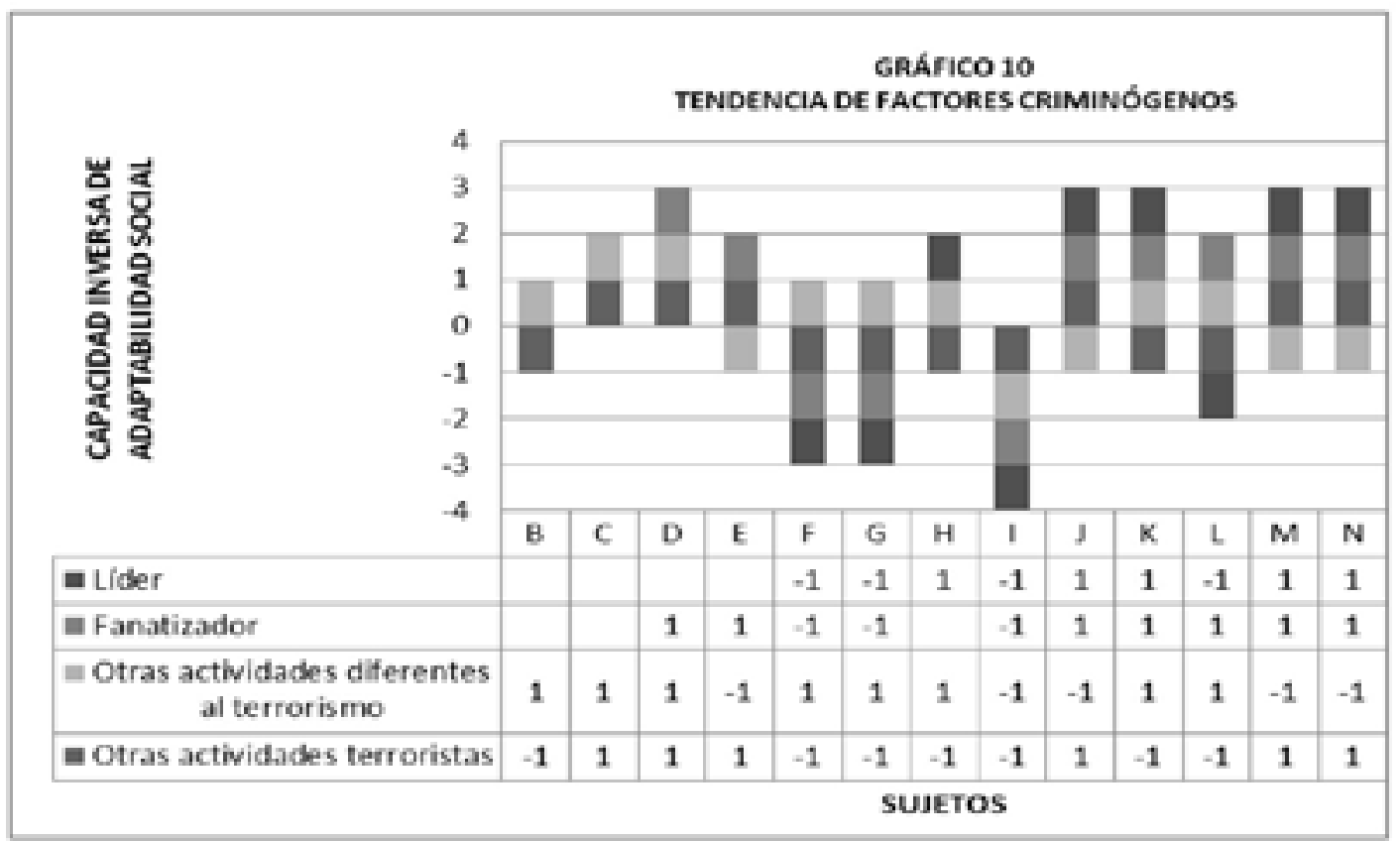




\begin{tabular}{|c|c|c|c|c|c|c|c|c|c|c|c|c|c|}
\hline \multirow{7}{*}{ 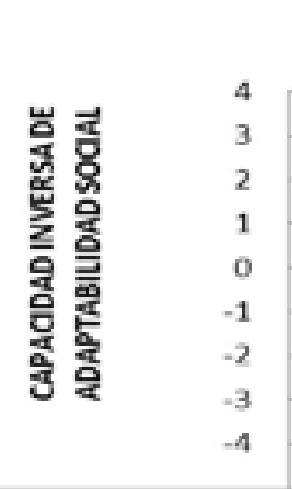 } & \multicolumn{13}{|c|}{$\begin{array}{c}\text { GRÁFICO } 11 \\
\text { TENDENCIA DE FACTORES CRIMINOG GENOS }\end{array}$} \\
\hline & & & & & & & & & & & & & \\
\hline & & & & & & & & & & & & & \\
\hline & & & & & & & & & & & & & \\
\hline & & & & & & & & & & & & & \\
\hline & & & & & & & & & & & & & \\
\hline & B & C & D & E & $F$ & G & $H$ & 1 & $J$ & K & I & $M$ & $\mathrm{~N}$ \\
\hline - Tánger & -1 & 1 & -1 & -1 & -1 & 1 & -1 & -1 & -1 & -1 & -1 & 1 & 1 \\
\hline E Fanatizador & & & 1 & 1 & -1 & 1 & -1 & -1 & 1 & 1 & 1 & 1 & 1 \\
\hline ETetuán & -1 & 1 & -1 & -1 & -1 & -1 & 1 & 1 & -1 & -1 & -1 & -1 & -1 \\
\hline $\begin{array}{l}\text { Aflo nacimiento } \\
\text { frecuencia }>1\end{array}$ & 1 & 1 & -1 & -1 & -1 & 1 & -1 & 1 & -1 & 1 & -1 & 1 & 1 \\
\hline
\end{tabular}

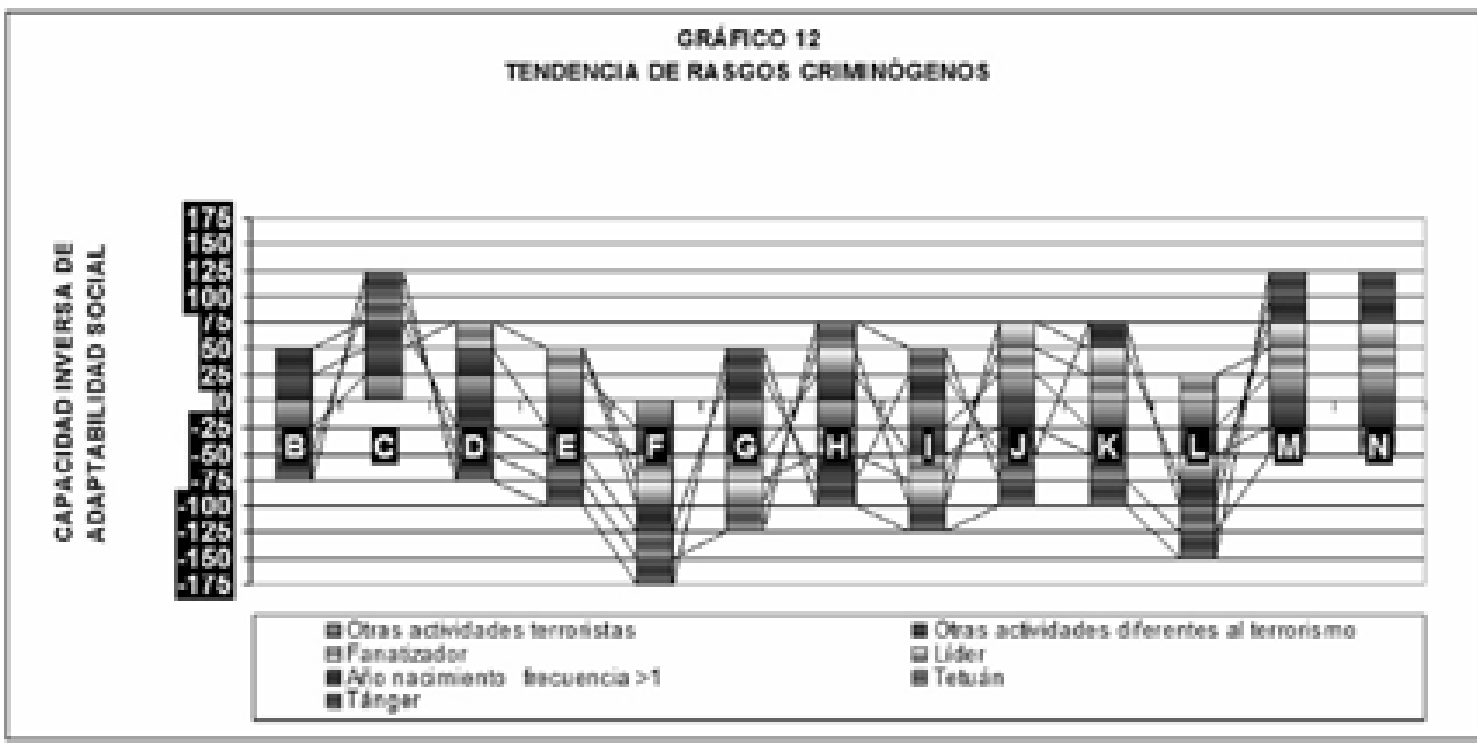




\section{BIBLIOGRAFÍA}

- AGNEW, R. (1992). “Foundation for a General Strain Theory of Crime and Delinquency". Ed. Criminology, Vol. 30, no 1, 1992.

- AKERS, R. L. (1998). "Social learning and social structure: A general theory of crime and deviance". Boston. Ed. Northeastern University Press.

- ALGORA, Ma D. (2005). "Terroristas y Terrorismo", en Centro Superior de Estudios de la Defensa Nacional Fundación Sagardoy, Monografías del CESEDEN, $\mathrm{n}$ 79, Terrorismo internacional: Enfoques y percepciones, Madrid. Ed. Ministerio de Defensa.

- ALLPORT, G. W. (1975). La personalidad. Su configuración y desarrollo. Barcelona. Ed. Herder.

- ALONSO-FERNÁNDEZ, F. (1994). Psicología del Terrorismo. Barcelona. Ed. Ediciones Científicas y Técnicas.

- ANZIT GUERRERO, R., El positivismo biológico en „la sociedad y el delito" (1947) de José Belbey, Ed. Facultad de Ciencias Jurídicas, Universidad del Salvador, en línea,

- <http://www.salvador.edu.ar/juri/ positivismo-anzit\%20guerrero.htm>

.[Consulta: 28 de octubre de 2007]

- AUdiEnCIA nACIONAL, Juzgado Central de Instrucción no 6, Expediente, Sumario 20/04, Carpeta 11 Documentación desclasificada. Madrid.

- AUdiencia nACIONAL, Sala de lo Penal, Sentencia 20/04. Madrid. ARISTEGUI, de G. (2005). La Yihad en España. Madrid. Ed. La Esfera de los Libros BANDURA, A. (1987). Teoría del aprendizaje social. Madrid. Ed. Espasa Calpe.

- BARBERET, R., y BARQUÍN, J. (2006). Justicia Penal Siglo XXI. Granada. Ed. Comares

- BELBEY, J. (1947). La sociedad y el delito. Buenos Aires. Ed. Claridad.

- ERKOWITZ, L. (1969). "The frustrationaggression hypothesis revisited, en Advances in Experimental Social Psychology", Vol. II. New York. Ed. Academy Press.

- BERKOWITZ, L. (1986). "Advances in experimental social psychology", Vol. 19. New York. Ed. Academic Press.

- BERKOWITZ, L. (1987). "Mood, selfawareness, and willingness to help", Ed. Journal of Personality and Social Psychology, no 52.

- BERKOWITZ,L. (1989)."Frustration-aggression hypothesis: Examination and reformulation", Ed. Psychological Bulletin, no 106.

- BLOGIA. En <http://mqh.blogia. com/2005/052703-clerigos-en-siria.php> [consulta: 8 de diciembre de 2008].

- CAMPAGNA, A. F. y HARTER, S. (1975). "Moral judgment in sociopathic and normal children", Ed. Journal of Personality and Social Psychology, no 31 (2).

- CLARKE, R. V. y CORNISH, D. B. (1985). "Modelling offenders decision: a framework for research and policy", en M. Tonry y N. Morris (Eds.), Crime and Justice, Vol. 6. Chicago. Ed. University of Chicago Press.

- CLECKLEY, H. (1976). The mask of sanity. St. Louis, USA. Ed. Moshy.

- Clemente, M. M. (1987). Delincuencia Femenina: Un enfoque psicosocial. Madrid. Ed. UNED.

- ClEMENTE, M., ESPINOSA, P. (2001). La Mente Criminal. Madrid. Ed. Dykinson.

- CLONINGER, C. R. (1987). "A systematic method for clinical description and classification of personality variants". Ed. Archives of General Psychiatry, no 44.

- ClONINGER, C. R. (1993). "Personality and psychopathology: neuroadaptative processes". New York. Ed. Oxford University Press.

- ClONINGER, C. R., PRZYBECK, T. R., SVARAKIC, D. M. y WETZEL, R. D. (1994).

- "The temperament and character inventory (TCI). A guide to its development and use". St. Louis, USA. Ed. Center for Psychobiology of Personality. 
- ClOWAR, R. A. y OHLIN, L. E. (1960). "Delinquency and Opportunity". New York. Ed. The Free Press.

- COHEN, A. K. (1971). "Delinquent Boys". New York. Ed. The Free Press CORÁN (Texto religioso).

- DIRECCIÓN GENERAL DE LA POLICÍA, Comisaría General de Información, Unidad Central de Inteligencia, (2004) Operaciones de la C.G.I. contra el terrorismo integrista islámico entre 1996/2004, Madrid.

- DOLLARD J., DOOB L., MILLER N., NOWERER O. H. y SEARS R. R. (1998).

- Frustration and aggression. London. Ed. Routledge.

- ELLIOT, D. S., y MENARD, S. (1977). Delinquent behaviour and delincuente peers: Temporal and developmental patterns. Unpublished manuscript.

- ELORZA, A. (2002). Umma: El integrismo en el Islam. Madrid. Ed. Alianza FARRINGTON, D. (1994). Psychological Explanations of Crime, Ed. Dartmouth, Aldershot.

- GARCÍA-ABADILLO, C. (2005).11-M La venganza Madrid. Ed. La Esfera de los libros

- GARCÍA ANDRADE, J. (1973). El hombre el delito y su mundo. Madrid. Ed. Maisal .

- GARCÍA ANDRADE, J. (1982). Raíces de la violencia. Madrid. Edición del autor.

- GARCÍA PABLOSDE MOLINA,A. (1988). Manual de criminología. Madrid. Ed. Espasa Calpe

- GINER, S. (1983). Sociología. Barcelona. Ed. Península.

- GOLEMAN, D. (1997). Inteligencia Emocional. Barcelona. Ed. Cairos.

- GÖPPINGER, H. (1975) Criminología. Madrid. Ed. Reus.

- HENGGELER, H. (1989). Delinquency in Adolescence. Newbury Park. Ed. Sage Publications.

- HIRSCHI, T. (2002). Causes of delinquency. New Brunswick. Ed. Transaction Publishers JORDÁN, J. (2004.) Coord., Los orígenes del Terror. Madrid. Ed. Biblioteca Nueva.

- JORDÁN, J. (2004). Profetas del miedo.
Pamplona. Ed. Universidad de Navarra.

- LAGUIA2000. En <http://www.laguia2000. com/medio-oriente/la-creacion-del-estadode- israel> [consulta: 6 de abril de 2016].

- LAQUEUR, W. (2003). La guerra sin fin. El terrorismo en el siglo XXI. Barcelona. Ed. Destino.

- LeBLANC, M. y FRECHETTE, M. (1989). Male Criminal Activity from Childhoo trough Youth. New York. Ed. Springer-Verlag.

- LILA, Ma S. (2004). "Psicología Social y Criminal", en Diploma de Especialización Profesional Universitario. Valencia. Ed. Universidad de Valencia.

- LILA, Ma S. (2004). "Sociología de la delincuencia", en Diploma de Especialización Profesional Universitario. Valencia. Ed. Universidad de Valencia.

- LOEBER, R. y DISHION, T. (1983). "Early predictors of male delinquency a review", Psychological Bulletin, no 94.

- LOSADA, T. y BAYT, AL-TAQAFA (1993). "La Mujer inmigrante marroquí en España", Congreso Mujeres, Democracia y Desarrollo en el Magreb. Madrid. Ed. Fundación Pablo Iglesias

- MACCOBY, E. E., y JACKLIN, C. N. (1974). "The psychology of sex differences". Stanford, CA. Ed. Stanford University Press

- McLAUGHLIN, E., MUNCIE, J. y HUGHES, G. (2003.), Criminal Perspectives. Essential Readings. London. Ed. Sage.

- MERTON, R. (1972). Teoría y estructuras sociales. México. Ed. FCE.

- MORILLAS, D. (2003). Análisis criminológico del delito de violencia doméstica. Cádiz. Ed. Universidad de Cádiz.

- MURILLO, Ma S. y LILA, Mã S. (2001). Psicología, en Diploma de Especialización Profesional Universitario, Preparación en ciencias policiales. Valencia. Ed. Universidad de Valencia.

- NYE, F. I. (1982). Family Relationships: rewards and costs. Bervely Hills. Ed. Nye PARSONS, T. (1968). La estructura de la acción social. Madrid. Ed. Guadarrama 
PARSONS, T. (1984). El sistema social. Madrid. Ed. Alianza.

- PATTERSON, G. R., REID, J., y DISHION, T. J. (1992). Antisocial boys. Eugene. Ed. Castalia

- PÉREZ GONZÁLEZ, M. R.(2004). “El islamismo en Marruecos: Riesgos y amenazas", Grupo de Estudios Estratégicos, № 185, noviembre, en http://www.gees.org/articulo/892/ [Consulta: 22 de enero de 2008].

- PHILIP, W., HARRIS, W., WELSH, N. y BUTLER, F. (2006). "Un siglo de justicia juvenil", en T. Barberet y J. Barquín, Justicia Penal Siglo XXI. Granada. Ed. Comares.

- PINATEL, J. (1974). Tratado de Derecho Penal y Criminología, Tomo III, Criminología. Caracas. Ed. Facultad de Derecho, Universidad Central de Venezuela

- RECKLESS,W.C. (1967). The crime problem. New York. Ed. Appleton-Century-Crofts.

- REISS, A. J. (1988). "Co-offending and criminal careers", en M. Tonry y N. Morris (Eds.), Crime and Justice, Vol. 10. Chicago. Ed. University of Chicago Press.

- RUIZ-ALMODÓVAR, C. (2007). "La Legislación de la familia en lospaísesárabes". Ayer, Revista de Historia Contemporánea, no 65. Madrid. Ed. Asociación de Historia Contemporánea.

- SÁNCHEZ J. (1993). Delincuencia Juvenil. Facultad de Derecho, Universidad Complutense. Madrid. Inédita.

- SÁNCHEZ, J. (2012). Manual de Clínica Criminológica. Perfil de peligrosidad criminal. Madrid, Tecnos.

- SANMARTíN, J. (1999). Violencia contra niños. Barcelona. Ed. Ariel.

- SANTO-DOMINGO, J., BAYÓN, C., CAÑAS, F., KASSEN, S., MARTÍNEZ, J. y RODRÍGUEZ VEGA, B. (1993). Guía para las prácticas de psiquiatría. Madrid. Universidad Autónoma de Madrid, Facultad de Medicina.

- SEPÚlVEDA, I y ARTEAGA, F. (2006). "Los trabajos de investigación: proceso, estructura y formato", en F. Arteaga (2006). Guía de Investigación sobre la paz, la seguridad y la defensa. Madrid. Ed. Instituto Universitario General Gutiérrez Mellado de investigación sobre la paz, la seguridad y la defensa.

- SUTHERLAND, E. H. y CRESSEY, D. R. (1978). Criminology. New York. Ed. J.B. Lippincott Co.

- SYKES, G. M. y MATZA, D. (1957). "Techniques of Neutralization: A Theory of Delinquency", Ed. American Sociological Review, XXII.

- SYKES, G. M. y MATZA, D. "Techniques of neutralization", en E. Mclaughlin, J. Muncie y G. Hughes (2003.), Criminal Perspectives. London. Ed. Sage.

- TARIJ. En <http://www.tarij.com/Paises/ Siria/Altos\%20del\%Golan- Guerra\%20 Yom\%20Kipur> [consulta: 3 de diciembre de 2008].

- TIMASHEFF, N. S. (1974). La teoría sociológica. México. Ed. Fondo de cultura Económica.

- TONRY, M. y MORRIS, N., (1988), "Crime and Justice", Vol. 10. Chicago. Ed. University of Chicago Press.

- VAllejo, J. coord. (2001). Psiquiatría, Esquemas de diagnóstico y tratamiento. Barcelona. Ed. JIMS.

- WILKINSON, J. y CANTER, S. (1982). Social Skills Training Manual: Assessment, Programme Design and Management of Training. Chichester. Ed. John Wiley and Sons ZIMRING, F. E. (1981). "Kids, groups and crime: some implications of a wellknown secret", Ed. Journal of Criminal Law and Criminology. 